\title{
Experimental Fragility Analysis of Cold-Formed Steel-Framed Partition Wall Systems
}

\author{
Craig Jenkins", Siavash Soroushian', Esmaeel Rahmanishamsi ${ }^{\mathrm{c}}$, and E. "Manos" Maragakis \\ ${ }^{a}$ Corresponding Author, Graduate Student, Department of Civil and Environmental Engineering, \\ University of Nevada, Reno, Reno, NV, 89557, email: cjenkins@unr.edu \\ b Structural Analyst, Advanced Technology and Research, Arup, San Francisco, CA, 94105, email: siavash.soroushian@arup.com \\ ${ }^{c}$ Ph.D. Candidate, Department of Civil and Environmental Engineering, University of Nevada, \\ Reno, Reno, NV, 89557, email: erahmanishamsi@unr.edu \\ d Professor, Dean of College of Engineering, University of Nevada, Reno, Reno, NV, 89557, email: maragaki@unr.edu
}

\begin{abstract}
A series of full-scale system-level experiments using a two-story steel braced-frame structure was conducted at the University of Nevada, Reno Network for Earthquake Engineering Simulation site in order to better understand the seismic performance of integrated ceilingpiping-partition systems. In this study, responses and behaviors of cold-formed steel-framed partition wall systems were critically assessed through several design variables. Experimental results led to the calculation of out-of-plane acceleration amplification factors and the development of fragility functions. Results show that the acceleration amplification factors for out-of-plane partition walls are comparable with the recommended amplification suggested by the code for flexible components.
\end{abstract}

\section{KEYWORDS}

Nonstructural Systems, Experimental Study, Fragility Analysis, Shake Table Simulation, Partition Wall System, Steel-Framed 


\section{Introduction}

Structural and nonstructural components of critical facilities play key performance roles during an earthquake. However, failures of nonstructural components make up the majority of earthquake damage [FEMA E-74, 2012]. Nonstructural components, such as partition wall systems, are more susceptible to damage because the shake intensities that trigger damage in these systems are much lower than those for structural components [Taghavi and Miranda, 2003]. Partition walls are prone to several forms of damage such as cracking of gypsum boards, rocking of partial height partitions, and complete collapse of full/partial height partitions. Nearly all of these damage mechanisms were observed during past earthquakes including the 1994 Northridge earthquake [Reitherman and Sabol, 1995], the 2010 Darfield (Canterbury) earthquake [Dhakal, 2010], and the 2010 Chile earthquake [Miranda et al., 2012]. Several experimental studies were conducted to evaluate the performance of light-gauge steel-stud partition wall systems. Damage reported from these experiments included cracking of gypsum boards, bending of studs, out-of-plane damage of partition walls, popping out of studs from top tracks, gypsum screw connection damage, track-to-slab connection damage (or failure) and collapse of partition walls [Bersofsky, 2004; Retamales et al., 2013; Soroushian et al., 2014a; Rahmanishamsi et al., 2015a-b; Wang et al., 2015].These experiments provided valuable data that was employed to help understand the performance characteristics of component-level and system-level partition walls. However, there is still a demand for more informational data regarding seismic responses of partition walls.

In attempt to provide additional resources about the seismic performance of partition

walls, a series of system-level tests were conducted at the University of Nevada, Reno as part of the Grand Challenge Project (NEESR-GC: Simulation of the Seismic Performance of 
Nonstructural Systems). This study investigated the response and failure mechanism of integrated ceiling-piping-partition systems installed in a full-scale, two-story steel braced-frame structure that spanned over three biaxial shake tables. Light-gauged steel-framed partition walls were evaluated through different design variables including: 1) framing systems, 2) partition wall heights, 3) partition wall geometries, 4) openings in partition walls, and 5) top connections. Experimental results were used to evaluate the performance of different top connections. In addition, out-of-plane acceleration amplification factors were computed and compared against the recommended amplification prescribed by ASCE 7-10 [2010]. Experiemental fragilities were developed based on damage caused by inter-story drift. In the following sections, a description of the test-bed structure and the partition wall variables is given. Then, the instrumentation and loading protocol are described followed by a summary of the observed damage. Next, the performance of top connections is evaluated. Acceleration amplification factor and experimental fragility curve results are also discussed. Finally, ranges of inter-story drift ratios that represent certain levels of damage in partition walls observed from this study and past experimental studies are compared.

\section{Experimental Setup}

\subsection{Test-bed Structure}

A test-bed structure was designed in order to assess the seismic performance of acceleration and drift sensitive nonstructural systems. This full-scale, two-story, two-by-one bay steel braced-frame structure spanned over three biaxial shake tables at the University of Nevada, Reno Network for Earthquake Engineering Simulation (UNR-NEES) site. The overall dimensions were approximately 7.5m (24.5 ft.) high, 3.5m (11.5 ft.) wide, and 18.3m (60.0 ft.) long (Fig. 1). 
Investigators were able to evaluate the response of acceleration and drift sensitive components by designing two test-bed configurations. While the primary elements of the structure (beams, columns, transverse bracing) were the same, the longitudinal brace properties and amount of additional attached floor masses were different. The first configuration, named "linear", used buckling restrained braces (BRB) with a high yield capacity, $283 \mathrm{kN}$ (64 kip), to achieve large floor accelerations. Additional attached floor masses were $30.7 \mathrm{kN}$ (6.9 kip) and $17.6 \mathrm{kN}$ (4 kip) for the first and second floors, respectively. The natural period for the linear configuration was found to be $0.20 \mathrm{sec}$. The second configuration, named "nonlinear", incorporated BRBs with a lower yielding capacity of $89 \mathrm{kN}$ (20 kip), to produce large inter-story drifts through the yielding of BRBs. The amount of additional mass was increased in this structure to $62.5 \mathrm{kN}$ (14 kip) for the first floor and $279.1 \mathrm{kN}$ (62.8 kip) for the second floor. The natural period for the nonlinear configuration was calculated as $0.34 \mathrm{sec}$. Figure $2(\mathrm{a}-\mathrm{b})$ shows the north and south bays of the first floor while Fig. 2c shows the entire test-bed structure. Figure 2(d-e) shows an example of a content room on the second floor.

\subsection{Partition Wall Specimens}

Over 100 light-gauged steel-framed partition walls were tested and evaluated during this study. Responses and behaviors were critically assessed through several design variables including: 1) framing systems, 2) partition wall heights, 3) partition wall geometries, 4) openings in partition walls, and 5) top connections. Table 1 tabulates the different partition variations and the partition wall layout is shown in Fig. 4. The nomenclature used is $\mathrm{PX}_{\mathrm{i}}-\mathrm{X}_{\mathrm{j}}$ where $\mathrm{P}$ stands for partition, $\mathrm{X}_{\mathrm{i}}$ is the specimen number, and $\mathrm{X}_{\mathrm{j}}$ is the floor location (F: first, $\mathrm{S}$ : second). For additional resources on partition walls, please refer to Rahmanishamsi et al. (2014). 
Typical partition walls were constructed from steel framing systems (studs and tracks) and gypsum boards. The web and flange dimensions of the studs and tracks were $88.9 \mathrm{~mm}(3.5$ in.) and $31.8 \mathrm{~mm}$ (1.25 in.), respectively, while the thickness was either $0.46 \mathrm{~mm}$ (18 mils) or $0.76 \mathrm{~mm}$ (30 mils). The naming designation, that will be used to describe stud and track properties herein, for a $0.46 \mathrm{~mm}$ (18mil) stud is $350 \mathrm{~S} 125-18$. The gypsum board thickness was $15.5 \mathrm{~mm}$ (5/8 in.). Thinner framing systems (350S125-18 studs and 350T125-18 tracks) and corner detailing, as shown in Fig. 5a, were considered as the commercial construction. Thicker studs (350S125-30) and tracks (350T125-30) along with a more robust corner connection represented the institutional construction. While \#8 self-drill screws were used for stud-track connections, \#6 self-drill screws were used for gypsum-stud and gypsum-track attachments. Also, shot pins (Hilti X-u27) were utilized for the track to concrete connections.

Full height partition walls considered in the test program consisted of full height studs paired with full or partial height gypsum boards. Partial height partition walls were either free standing or braced. Braced partial height walls included two types of bracing mechanisms. The first utilized out-of-plane 45 degree steel studs to connect the tops of the partition walls to the deck above, as shown in Fig. 3a. The second bracing mechanism encompassed two out-of-plane 45 degree steel wires attaching the ceiling system to the above deck. The tops of partition walls were then screwed to the ceiling grid members in order to minimize movement within the partition walls, as shown in Fig. 3b. Studs and gypsum boards stopped $152.4 \mathrm{~mm}$ (6.0 in.) above the ceiling elevation for specimens that included steel studs as the bracing. In the specimen that involved wire bracing, the studs and gypsum walls stopped at the ceiling elevation. The south and north content rooms (shown in Fig. 4) were made from free standing and braced partial height partitions, respectively. Moreover, three types of wall shapes were considered in this 
study: 1) single walls (no return wall) named ' $S$ ', 2) one return (transverse) wall with one longitudinal wall named ' $L$ ', and 3) one return wall with two longitudinal walls named ' $C$ '. Besides shape variations, several doors and windows were built in partitions to investigate the effect of openings in partition walls.

The response of different partition connections was critically assessed during this experiment. The bottom connection of all partition walls were composed of track-to-deck attachments with shot pins, track-to-stud and gypsum-to-track connections using mentioned selfdrilling screws. However, three types of detailing named slip track, full, and sliding/frictional were used for top connections. In the slip track connection detail, the track was only connected to the deck through Hilti X-u27 shot pins. The connection from track-to-stud was omitted to allow the studs to slide within the track (Fig. 5b). Similar to the slip track connection detail, the full connection detail used Hilti X-u27 shot pins to connect the track to the deck. However, a trackto-stud connection with self-drilling screws was included in the full connection detail (Fig. 5c). In the sliding/frictional connection (Fig. 6$)$ a thin $6 \mathrm{~mm}$ by $25 \mathrm{~mm}$ steel plate $(0.25$ by 1.0 in.) was attached to the concrete deck by shot pins (Hilti X-U32S15). The top track was then sandwiched between the plate and $19 \mathrm{~mm}$ by $25 \mathrm{~mm}$ by $305 \mathrm{~mm}(0.75$ by 1.0 by $12.0 \mathrm{in}$.) rectangular tubing by means of two fasteners (screw and spring washer) spaced $178 \mathrm{~mm}(7.0$ in.) apart. It should be mentioned that pre-drilled holes with diameters equal to the track width $(88.9 \mathrm{~mm}(3.5$ in.)) allowed for the tubing to be connected to the steel plate without connecting the track. The studs were connected to the 18 gage slotted track using the $12.7 \mathrm{~mm}(0.5 \mathrm{in}$.$) wafer head screws.$ Additional information about the details and performance of the sliding/frictional connection can be found in Araya-Letelier and Miranda [2012]. 
In addition to the described partition walls, the performance of shaft walls was also evaluated during the test program. In this study, shaft walls were installed in the North Bay on the first floor, designated by the partition walls labeled P1-F, P7-F, and P8-F in Fig. 4. These walls were constructed from one layer of $25.4 \mathrm{~mm}$ (1.0 in.) thick Fire-Shield Shaftliner board on one side and two layers of $12.7 \mathrm{~mm}$ (0.5 in.) Fire-Shield $\mathrm{C}$ gypsum boards on the other. The gypsum boards were attached to $50.8-12.7 \mathrm{~mm}$ (2-0.5 in.) steel C-H studs by S (drywall) screws (Fig. 5d-e). The top and bottom track was connected to their corresponding deck by shot pins. While their bottom attachment was similar to the previously discussed partition walls (Hilti X$\mathrm{u} 27$ shot pins), two types of details were used for their top connection. During all the linear and the first nonlinear tests, neither the studs nor gypsum boards were connected to the top track (named "Shaft Wall 1"), shown in Fig. 5f. During the remaining tests, the studs and gypsum boards were connected to the top track via \#8 and \#6 self-drill screws, respectively (named “Shaft Wall 2").

\subsection{Instrumentation}

The responses of structural and nonstructural components were monitored by nearly 400 sensor channels with a sampling frequency of $256 \mathrm{~Hz}$. A 4-pole low-pass Butterworth filter with a cutoff frequency of $50 \mathrm{~Hz}$ was applied to all recorded responses [Soroushian et al., 2014b]. The structure movement was measured by a combination of accelerometers and string potentiometers. These instruments were placed at column locations and the middle of floor slabs (see Fig. 7).

The responses of nonstructural components were recorded by displacement transducers, string potentiometers, and accelerometers. Displacement transducers were placed at the top and bottom of partition specimens with vertical or horizontal orientations (Fig. 8a-c). Diagonal string 
potentiometers were also attached as shown in Fig. 8d. Uniaxial accelerometers were located at the center of some partition walls at the ceiling elevation (Fig. 8e).

\section{Loading Protocol}

A total of 59 ground motions were applied to the test-bed structure. A spectrum-matching procedure was adopted to artificially generate shake table motions. The AC 156 [ICC, 2010] parameters, used to develop the targeted acceleration spectra, were defined based on a story height ratio $(\mathrm{z} / \mathrm{h})$ of 0.5 , and the design spectral response acceleration at short periods $\left(\mathrm{S}_{\mathrm{ds}}\right)$ of $2.5 \mathrm{~g}$ [Soroushian et al., 2014b]. In addition to the target spectra at the shake table, it was a goal to attain the target spectra at the second floor. This goal was accomplished using the algorithms defined by Soroushian et al. [2011].

Forty-two of the 59 motions were applied to the linear test-bed structure; 12 were titled "Unmodified Linear", and 30 were titled "Modified Linear". The shake tables for the Unmodified Linear and Modified Linear motions were set to represent the target spectrum at the table and at the second floor levels, respectively. Motion durations during the linear portion of testing were $30 \mathrm{sec}$. The remaining (17 out of 59) motions were applied to the nonlinear test-bed configuration. Motions during this portion of testing were titled "Nonlinear" and the shake tables were set to represent the target spectrum at the table level. Durations for nonlinear motions were reduced to $10 \mathrm{sec}$. Figure 9 shows the comparison of $5 \%$ damped spectra achieved on the shake table and the second floor during $50 \%$ of full scale motions (50\% IM) [Soroushian et al., 2014b].

A total of 8 tests were conducted in this study. Linear testing consisted of five tests named, Linear-1 through Linear-6 (example L-1) in which a combination of the Unmodified Linear and Modified Linear motions were applied. It should be mentioned that test Linear-4 was removed from testing to ensure a timely project completion. The remaining linear experiments 
were not consecutively updated because the schedule and documentation were already assigned. The remaining three tests were nonlinear, named Nonlinear-1 through Nonlinear-3 (example NL1) and utilized the Nonlinear motions. The summary of peak floor accelerations and inter-story drift ratios in linear and nonlinear structures are presented in Table 2. The partition wall specimens were not replaced throughout the five linear tests (L-1 to L-6) and the first nonlinear test (NL-1) because it was anticipated that minimum partition wall damage would occur during linear testing due to the low inter-story drift demand on partition walls. However, partition wall specimens were replaced after each of the nonlinear tests because damage was expected to transpire during nonlinear tests due to the large inter-story drift. Table 3 shows the partition wall test matrix for the linear and nonlinear tests.

\section{Damage Observation}

The seismic performance of partition walls was evaluated through observed damage mechanisms. After each ground motion was applied to the structure, the damage to partition walls was assessed and then recorded in damage descriptions. Then, with the aid of pictures, videos, and noted descriptions, the observed damage was summarized. Table 4 outlines several damage mechanisms and shows which individual partition wall experienced the damage. A few of the most common damage mechanisms observed during the experiment are shown in Fig. 10 and described below. Specimens with full height studs and partial height gypsum experienced damage such as the formation of plastic hinges approximately 305mm (12 in.) below the top connection (Fig. 10a). In braced partial height partitions, failure of 45 degree stud connections was recorded (Fig. 10b). In specimens that involved institutional and commercial corner detailing, observed damage encompassed the tops of studs popping out of the track (Fig. 10c) and tape damage (Fig. 10d). Typical damage to gypsum boards near door and window openings 
included cracks extruding from the corners (Fig. 10e). Figure 10f shows an example of the damage described as field screw popout (when the head of the screw dislodges from the plaster coating). Damage to the ends of wall sections (named boundary locations) included screws and/or the stud pulling out from the gypsum board, as shown in Fig. 10g. More excessive damage involved stud deformation or complete pullout from the top track (Fig. 10h).

In the partitions with full connections, plastic hinging (Fig. 10i), boundary stud damage, and field screw pop out in single ' $S$ ' shaped walls were observed. In addition, the corner connections with ' $\mathrm{C}$ ' and ' $\mathrm{L}$ ' shapes experienced separation of the return and longitudinal walls, crushing of gypsum board corners, and tape damage. Partitions with the slip track connections experienced studs sliding out of the track at boundary locations and crushing of gypsum board corners for single ' $\mathrm{S}$ ' shape walls. Corner connection damage involved studs sliding out from the top track causing separation of the return and longitudinal walls and crushing of gypsum boards in the top corners (Fig. 10j). Damage observed in the sliding/frictional connection included field screw pop out, plastic hinging of studs, and boundary stud pullout (Fig. 10k) in single 'S' shape walls. While some minor tape damage was observed in corner connections, return and longitudinal walls never separated from each other.

\section{Experimental Results}

\subsection{Performance of Top Connections}

The performance of top connections was compared by considering the ratio of partition drift over the maximum story drift. Ratio values close to one correspond to a fixed connection meaning that the partition drifts were similar to the floor drifts. Values close to zero correspond to isolated partition walls, or when the partition wall experienced lower drifts than the floor drifts. Some factors that can cause a lower partition/floor drift ratio include connection detailing 
or damage. The performance of top connections was evaluated for the three nonlinear tests (Fig. 10). As shown, the full and shaft wall 2 connections had the highest partition/floor drift ratio because of the stud-to-track connection. This connection forced the top and bottom of the partition wall to move like the top and bottom floors, respectively. When the drift ratio increased, the partition/floor drift ratio decreased, mainly due to the cumulative damage in the top connections. The slip track connection had the lowest partition/floor drift ratio because the top of stud was not connected to the track. Since there was no connection between the stud and track, the partition wall performed as an isolated wall causing the ratio to approach zero. It should be noted that the partition specimens used in test NL-1 were not replaced after the linear testing, therefore, the reuse of specimens and possible cumulative damage in top connections led to similar behavior regardless of the type of top connection.

\subsection{Partition Acceleration Amplification}

Acceleration amplification $\left(a_{p}\right)$ factors for ten out-of-plane partition walls were calculated for each of the ground motions (59 total motions) applied to the structure. Table 5 shows the statistics (maximum, minimum, and median) calculated for each partition wall. The amplification factors were calculated by taking the ratio of the peak partition acceleration over the peak floor acceleration for every connection to adjacent slabs. As an example, partitions that were full or braced partial height walls included two separate amplification factors, named "Top" and "Bottom". Partitions with only one connection, such as free standing partitions, only had one amplification factor (Bottom). As the table shows, the amplification factors for linear tests (42 amplifications) range (approximately) from 1.5 to 2.5 with a median value of 2.1 . The nonlinear tests (17 amplifications) produced similar results that range (approximately) from 1.8 to 2.5 with a median value of 2.3. ASCE 7-10 [2010] suggests that the maximum amplification is 2.5 for 
flexible components. The median value for both tests (all 59 amplifications), labeled "All" in Table 5, was 2.2. The results justify the recommended value since the median (2.2) is less than 2.5 .

\subsection{Seismic Fragility Analysis}

Experimental results for cold-formed steel-framed partition walls were used to assess the seismic vulnerability of partitions through fragility functions. A fragility function is a conditional statement (Eq. 1) that relates the probability of a component exceeding a level of damage, known as damage state (DS), when subjected to a particular engineering demand parameter (EDP) [Porter et al., 2007]. The EDP considered for this study was inter-story drift due to the drift sensitive nature of partition walls. Three DS's (Table 6) were developed using the FEMA P-58 [2012] framework and the DS's suggested by the State University of New York at Buffalo (UB) [Davies et al., 2011 and Retamales et al., 2013]. The defined DS's are based on level of damage observed and the required repair action. The observed damage mechanisms during the experiments were categorized into the defined DS's. Then, the drift ratio that initiated the damage was recorded for each of the partition specimens. Table 7 shows the minimum drift ratio that triggered each DS for the partition specimens that experienced damage.

It should be mentioned that in this study, the damage defined as field screw pop out was considered under the first, or minor, DS. Field screw pop out occurs when the head of the field screw dislodges from the coating compound and can transpire at relatively low inter-story drifts. It is believed that this damage is an indication of plastic hinging occurring in field studs in which the repair actions include possible removal of gypsum boards and replacement of studs. However, the correlation between the drift ratio initiating field screw pop out and the drift ratio initiating plastic hinging could not be made until the gypsum boards were removed from the 
studs at the end of the test. Therefore, due to testing procedure limitations, the field screw pop out damage is considered DS1 and the plastic hinging of field stud damage is considered DS3. It is recommended that additional studies be conducted in order to better understand the correlation between the two damages.

Experimental fragility functions were developed using Method A, outlined by Porter et al. [2007], which requires that all specimens failed at a target EDP. A summary of the fragility parameters, median and dispersion, determined using Equations 2 and 3, respectively, are shown in Table 8. The following fragilities are deemed acceptable because the Lilliefors goodness-of-fit test passed at the 5\% significance level.

$$
F(e d p)=\Phi\left(\frac{\ln \left(\frac{e d p}{x_{m}}\right)}{\beta}\right)
$$

where $\Phi$ is the normal cumulative distribution function, $e d p$ is the triggering drift ratio per specimen, and $x_{m}$ and $\beta$ are the fragility parameters, median and dispersion, respectively.

$$
\begin{gathered}
x_{m}=\exp \left(\left(\frac{1}{M}\right) \sum_{i=1}^{M} \ln (e d p)\right) \\
\beta=\sqrt{\left(\frac{1}{M-1} \sum_{i=1}^{M}\left(\ln \left(\frac{e d p}{x_{m}}\right)\right)^{2}\right)^{2}+\beta_{u}{ }^{2}}
\end{gathered}
$$

where $M$ is the number of specimens tested to failure, $i$ is the specimen index, and $\beta_{u}$ is 0.25 because the tests met at least one of the criteria listed by Porter et al. [2007].

Figure 12(a-c) presents individual fragility curves for partition specimens as well as a combination of all specimens labeled "All". As shown, the fragilities for DS3 (Fig. 12c) are all the same because the plastic hinging of field stud damage could not be observed until the gypsum wallboards were removed at the end of testing. Figure $12 \mathrm{~d}$ presents a summary of the 
three DS combinations. As shown, the DS's are in consecutive order with median floor drift ratios of $0.99 \%, 1.61 \%$ and $2.34 \%$.

\subsection{Comparison to Past Experimental Studies}

The ranges of inter-story drift ratios that represent the three partition wall DS's are compared for this study and past experimental studies (Table 9) [Restrepo and Bersofsky, 2011; Retamales et al., 2013; and Wang et al., 2015]. When comparing the ranges from DS1, the lower drift percentage for the experiments evaluated by Restrepo and Bersofsky [2011] and Retamales et al. [2013] are close to the drift experienced in this experiment (UNR). However, when comparing the higher drift percentage, UNR observed a much higher drift $(2.64 \%)$. The range of drift percentages observed at DS2 is higher for UNR (2.64\%) than all past experiments. The drift percentages recorded for DS3 are similar between all the experimental studies. The range differences between experiments can be due to distinct design variables used for each individual experiment. Examples that can contribute to these discrepancies include loading protocol, experimental setups (housing components, specimen configurations, uncertainties in material properties), detailing, or DS definitions.

\section{Summary}

This study investigated the response and failure mechanism of nonstructural components through a series of full-scale testing conducted at the University of Nevada, Reno NEES site. A two-story, two-by-one bay steel braced-frame structure, that spanned over three biaxial shake tables, was used to house the nonstructural components. The performance of light-gauged steelframed partition walls were evaluated through design variables including: 1) framing systems, 2) partition wall heights, 3) partition wall geometries, 4) openings in partition walls, and 5) top connections. Experimental results include the performance evaluation of top connections, out-of- 
plane acceleration amplification factors, and fragility curves based on damage caused by interstory drift. The ranges of inter-story drifts observed from this experiment were compared to drifts observed in past experimental studies. The major findings are summarized as follows:

- When evaluating the performance of top connections (full, slip track, and sliding/frictional), results show that as the drift ratio increased, the partition/floor drift ratio decreased because of the cumulative damage in the top connections.

- Damage to the full connection included plastic hinging of field studs and field screw pop out.

- The slip track connection reduced the amount of plastic hinging and field screw pop out, but experienced excessive corner damage.

- Damage to the sliding/frictional connection involved plastic hinging of field studs and field screw pop out, however, it only encountered minor tape damage in corner locations.

- The computed acceleration amplification factors for out-of-plane partition walls justify the ASCE 7-10 [2010] code's recommendation of a maximum amplification factor of 2.5 for flexible components.

- Investigators were unable to observe if the field screw pop out damage was an indication of plastic hinging forming in field studs until the gypsum boards were removed at the end of testing. Therefore, it is recommended that additional studies be conducted in order to better understand the correlation between the inter-story drift that initiates field screw pop damage and the drift that initiates plastic hinging in field studs. 
- Experimental fragility curves are in consecutive order with the median drift ratios for DS1, DS2, and DS3, as $0.99 \%, 1.61 \%$, and $2.34 \%$ respectively.

- Results show that after comparing the ranges of inter-story drifts (from past experimental studies to the current study), drifts observed during the UNR experiment are higher for DS1 and DS2, but are similar for DS3 than the drifts experienced from other studies.

\section{ACKNOWLEDGEMENTS}

This material is based upon work supported by the National Science Foundation under Grant No. 0721399. This Grand Challenge (GC) project to study the seismic response of nonstructural systems is under the direction of M. Maragakis from the University of Nevada, Reno and Co-PIs: T. Hutchinson, A. Filiatrault, S. French, and B. Reitherman. Any opinions, findings, conclusions or recommendations expressed in this document are those of the investigators and do not necessarily reflect the views of the sponsors.

\section{REFERENCES}

Araya-Letelier, G., and Miranda, E. [2012] "Novel Sliding/Frictional Connections for Improved

Seismic Performance of Gypsum Wallboard Partitions," Fifteenth World Conference on Earthquake Engineering, Lisbon, Portugal.

ASCE (American Society of Civil Engineers) [2010] Minimum Design Loads for Building and

Other Structures, Standard ASCE/SEI7-10, Reston, Virginia.

Bersofsky, A. [2004] “A Seismic Performance Evaluation of Gypsum Wallboard Partitions,” M.S. thesis, University of California, San Diego, California.

Davies, R., Retamales, R., Mosqueda, G., and Filiatrault, A. [2011] "Experimental Seismic 
Evaluation, Model Parameterization, and Effects of Cold-Formed Steel-Framed Gypsum Partition Walls on the Seismic Performance of an Essential Facility," Technical Report MCEER-11-0005, University at Buffalo, State University of New York, New York.

Dhakal, R. [2010] "Damage to Non-structural Components and Contents in 2010 Darfield Earthquake," Bulletin of the New Zealand Society for Earthquake Engineering, Vol. 43, No. 4, 404-411.

FEMA E-74 (Federal Emergency Management Agency) [2012] Reducing the Risks of Nonstructural Earthquake Damage: A Practical Guide, Redwood City, California.

FEMA P-58-1 (Federal Emergency Management Agency) [2012] Seismic Performance Assessment of Buildings Volume 1- Methodology, Redwood City, California.

ICC Evaluation Service: AC 156 [2010] Acceptance Criteria for Seismic Certification by Shake-Table Testing of Nonstructural Components, ICC Evaluation Service.

Jenkins, C., Soroushian, S., Rahmanishamsi, E., Maragakis, M. [2015] "Experimental Fragility Analysis of Cold-Formed Steel-Framed Partition Wall Systems," Structures Congress, ASCE, Portland, Oregon.

Miranda, E., Mosqueda, G., Retamales, R., and Pekcan, G. [2012] "Performance of Nonstructural Components during the 27 February 2010 Chile Earthquake," Earthquake Spectra, Vol. 28, No. S1, 453-471.

Porter, K., Kennedy, R., and Bachman, R. [2007] “Creating Fragility Functions for PerformanceBased Earthquake Engineering,” Earthquake Spectra 23, 471-489.

Rahmanishamsi, E., Soroushian, S., and Maragakis, E. M. (2014) "System-Level Experiments on Ceiling/Piping/Partition Systems at UNR-NEES Site," The Tenth U.S. National Conference on Earthquake Engineering 10NCEE, Anchorage, Alaska. 
Rahmanishamsi, E., Soroushian, S., and Maragakis, E. M. (2015a) "Cyclic Shear Behavior of Gypsum Board-to-Steel Stud Screw Connections in Nonstructural Walls," Earthquake Spectra, In-press.

Rahmanishamsi, E., Soroushian, S., and Maragakis, E. M. (2015b) "Analytical Model for the Seismic Performance of Cold-Formed Steel-Framed Gypsum Partition Walls,” Structures Congress, ASCE, Portland, Oregon.

Reitherman, R., and Sabol, T. [1995] "Nonstructural Damage," Chapter 11 in Northridge Earthquake of January 17, 1994 Reconnaissance Report, Supplement C to Earthquake Spectra 11, Oakland, California, 453-514.

Restrepo, J. I., and Bersofsky, A. M. [2011] "Performance characteristics of light gage steel stud partition walls," Thin Walled Struct., 49, 317-324.

Retamales, R., Davies, R., Mosqueda, G., and Filiatrault, A. [2013] “Experimental Seismic Fragility of Cold-Formed Steel Framed Gypsum Partition Walls," J. Struct. Eng., Vol. $139,1285-1293$.

Soroushian, S., Maragakis, E. M., Itani, M., Pekcan, G., and Zaghi, A. [2011] “Design of a TestBed Structure for Shake Table Simulation of the Seismic Performance of Nonstructural Systems," Structures Congress, ASCE, Las Vegas, Nevada.

Soroushian, S., Maragakis, E. M., Ryan, K., Sato, E., Sasaki, T., Okazaki, T., and Mosqueda, G. [2014a] "Seismic Simulation of Integrated Ceiling-Partition Wall-Piping System at EDefense, Part 2: Evaluation of Nonstructural Damage and Fragilities," J. Struct. Eng., Under Review.

Soroushian, S., Maragakis, E. M., Zaghi, A. E., Rahmanishamsi, E., Itani, M., and Pekcan, G. 
[2014b] "Response of a 2-Story Test-Bed Structure for the Seismic Evaluation of Nonstructural Systems," Earthquake Engineering and Engineering Vibration, Accepted. Taghavi, S., and Miranda, E. [2003] "Response Assessment of Nonstructural Building Elements,” Technical Rep. PEER 2003/05, Pacific Earthquake Engineering Research Center, University of California, Berkeley, California.

Wang, X., Pantoli, E., Hutchinson, T. C., Restrepo, J. I., Wood, R. L., Hoehler, M. S., Grzesik, P., and Sesma, F. H. [2015] "Seismic Performance of Cold-Formed Steel Wall Systems in a Full-Scale Building,” J. Struct. Eng. 
Figure 1
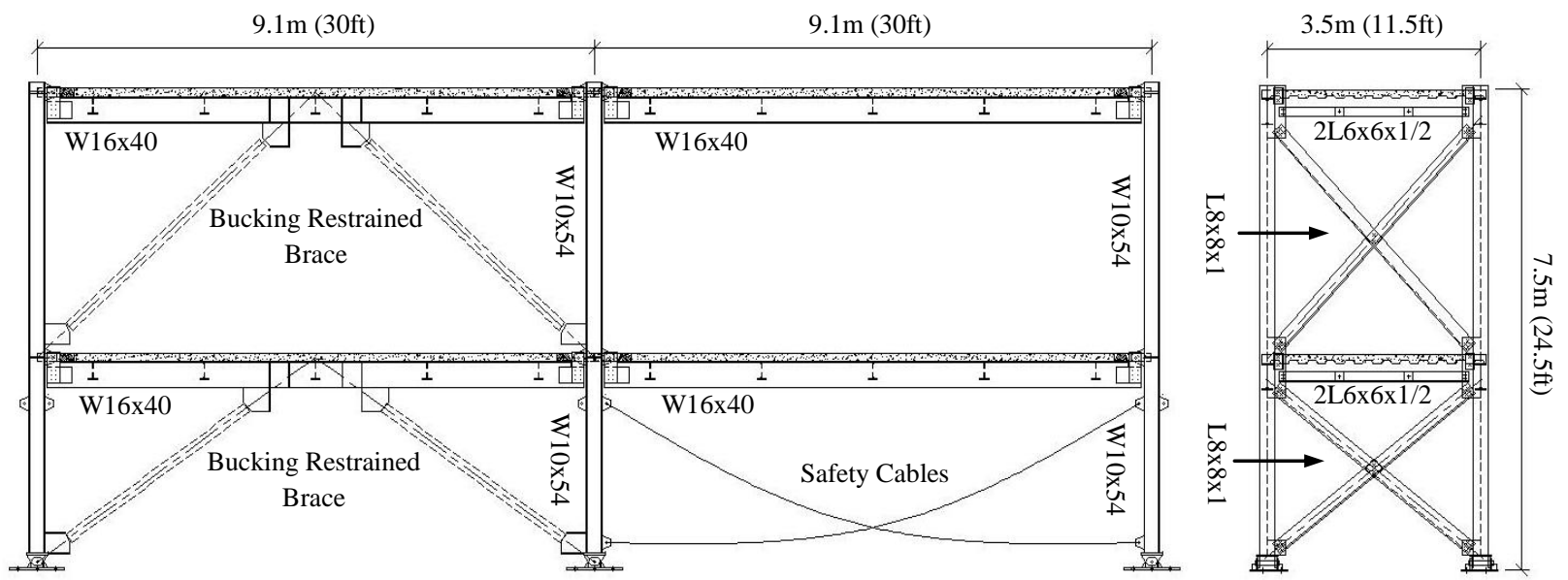

Fig. 1. Test-bed Structure: (left) longitudinal view, (right) transverse view 
Figure 2

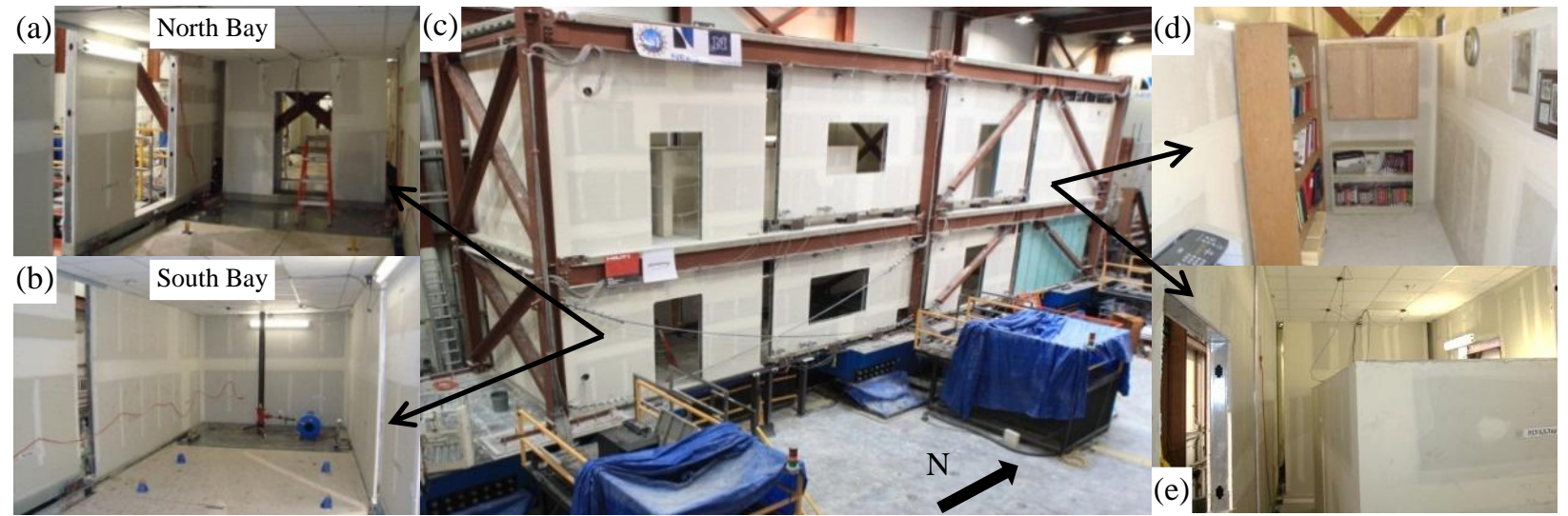

Figure 2 Figure 2

\section{.} ren

(d)

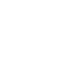


(a)

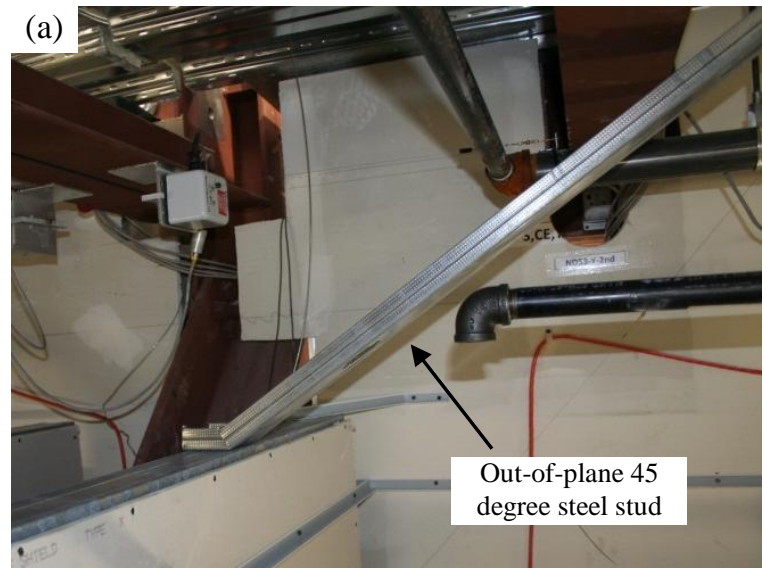

(b)

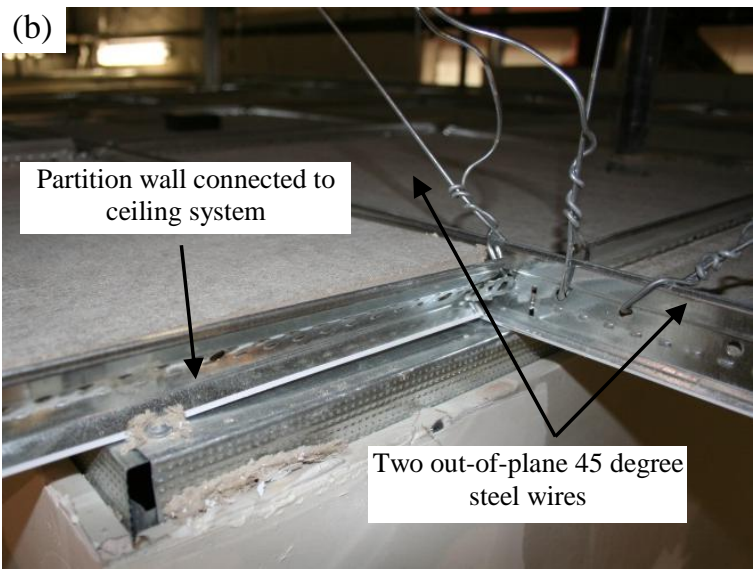

Fig. 3. Bracing Mechanisms for Partial Height Partition Walls

Figure 


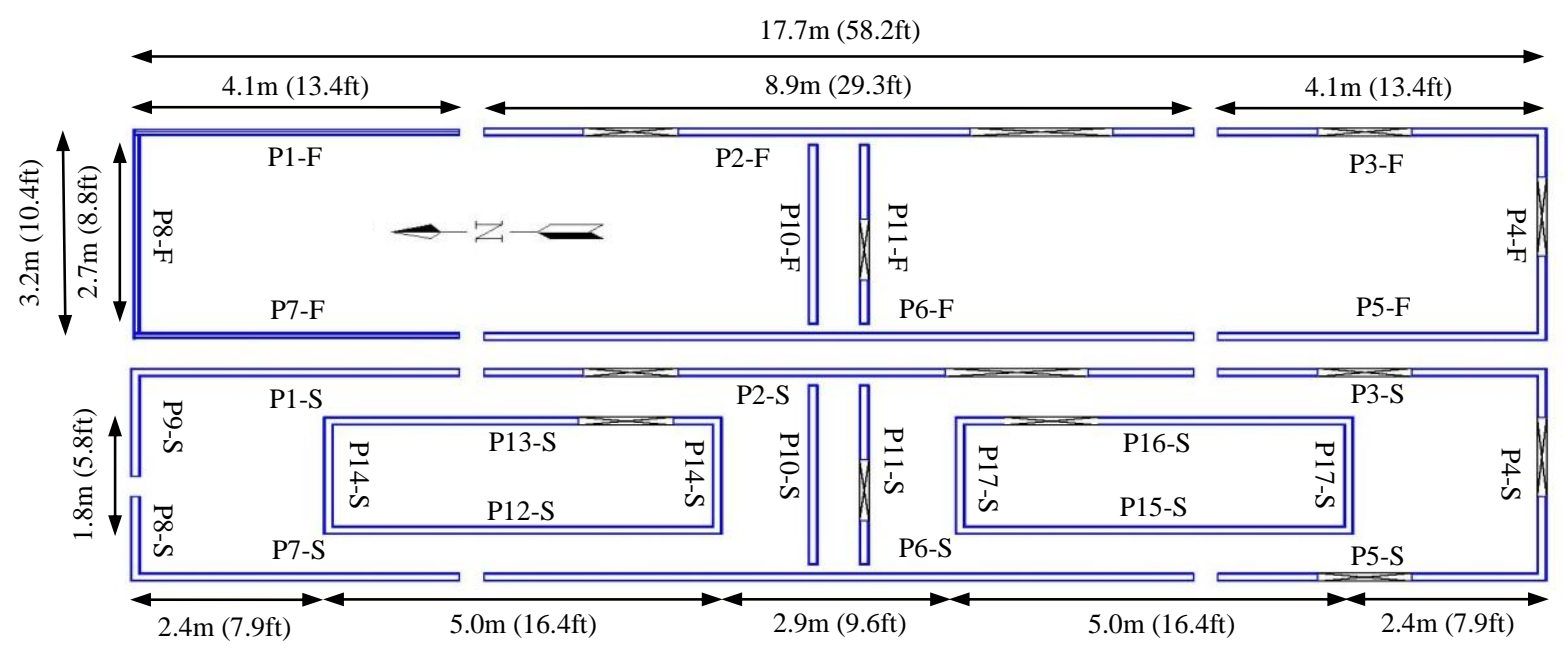

Fig. 4. Partition Wall Layout: (top) first floor, (bottom) second floor 


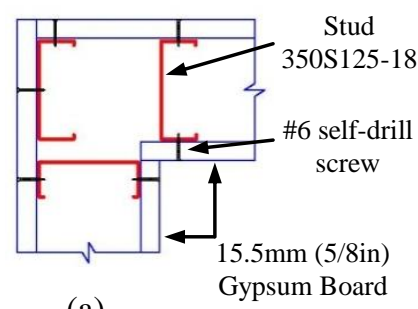

(a)

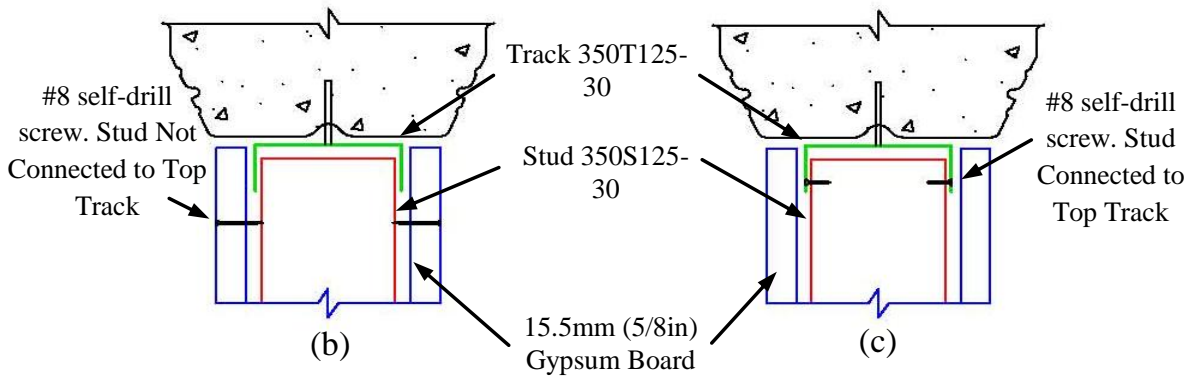

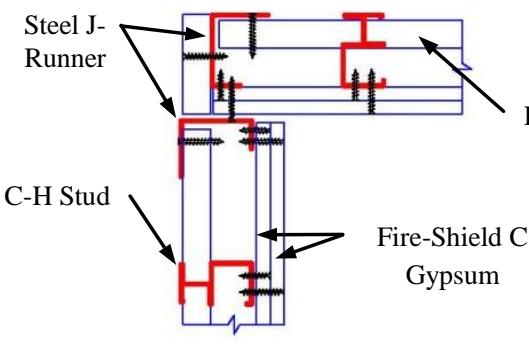

(d)

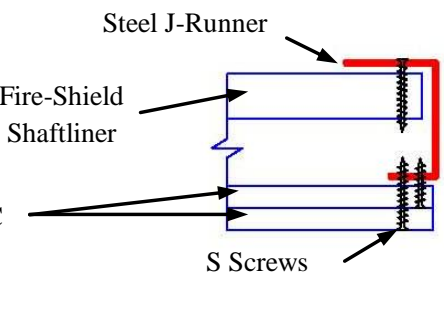

(e)

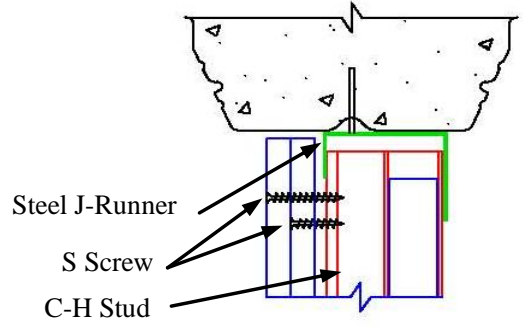

(f)

Note: Only a few partition wall connections are shown.

Fig. 5. Examples of Partition Wall Connections: (a) commercial corner, (b) slip track top connection, (c) full top connection, (d) shaft wall corner, (e) shaft wall end, and (f) shaft wall 1 top connection 
Figure 6
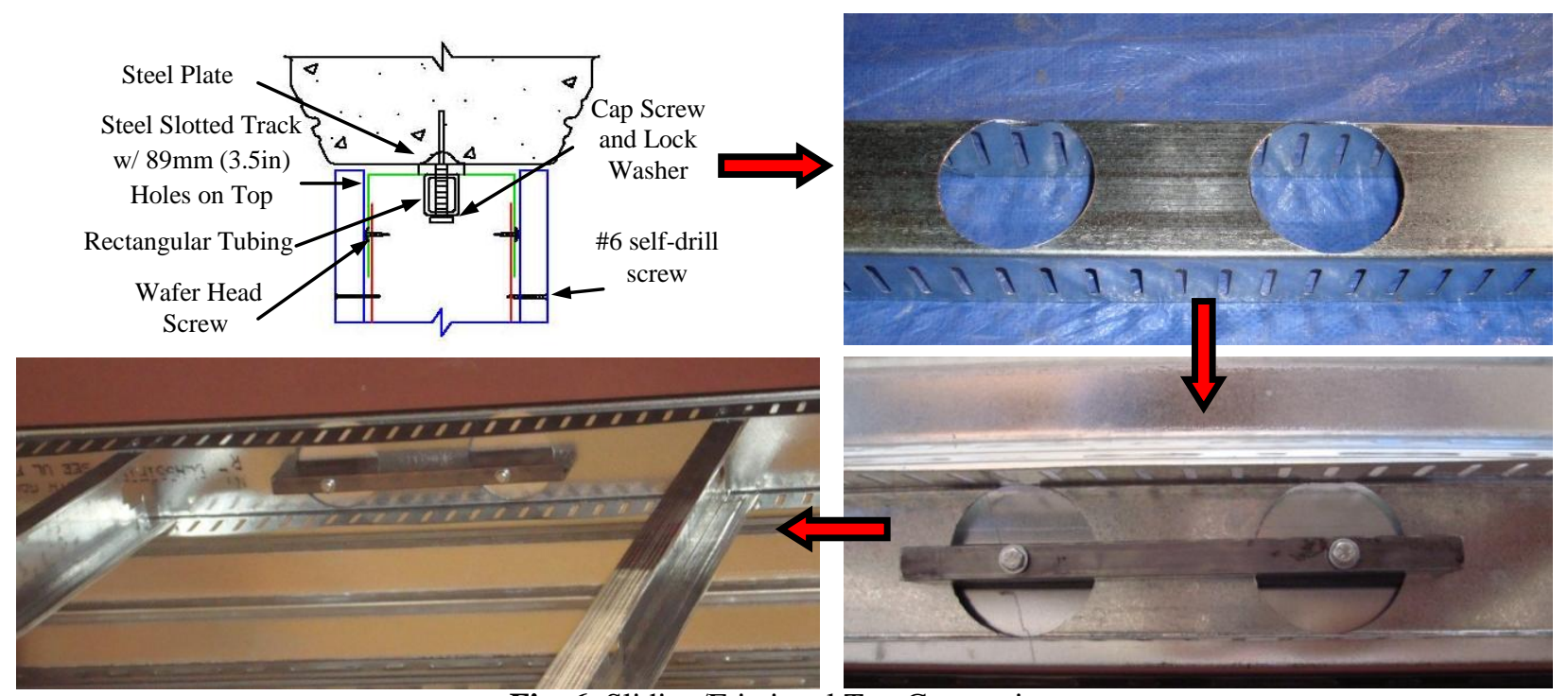

Figure 6

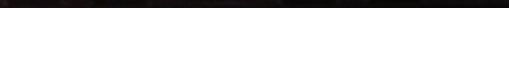

(n)

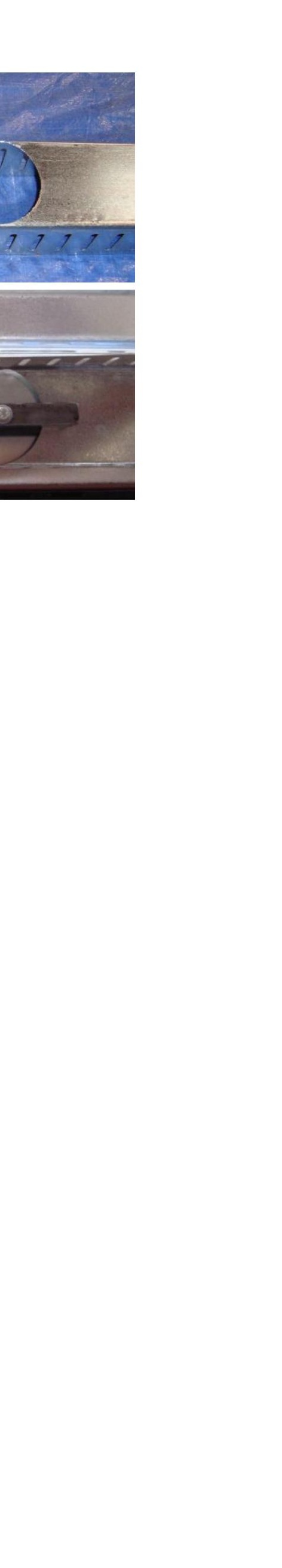




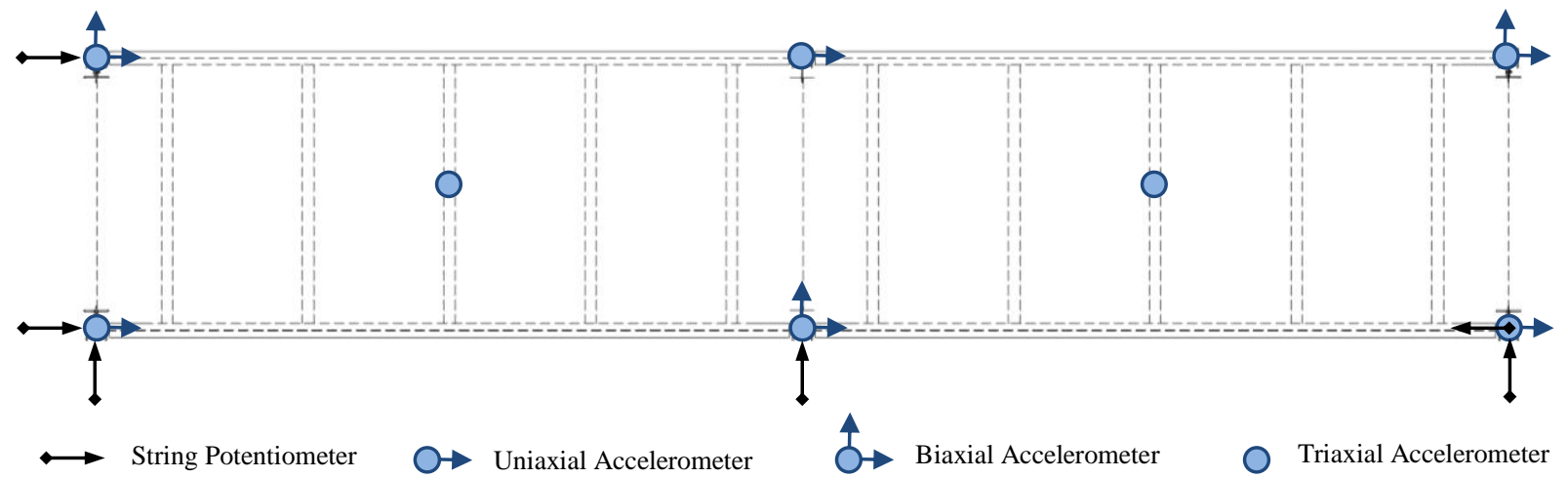

Fig. 7. Typical Structural Instrument Location [Source: Jenkins et al., 2015] 


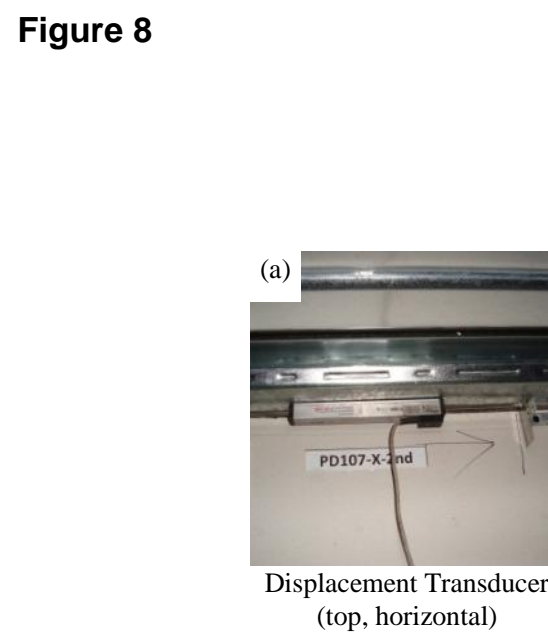

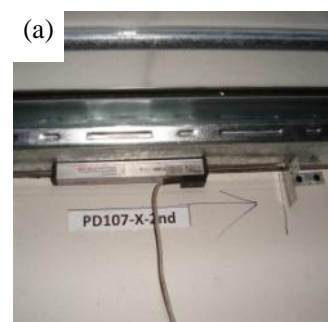

Figure 8
Displacement Transducer
(top, horizontal)

Figure 8
Displacement Transducer (bottom, horizontal)

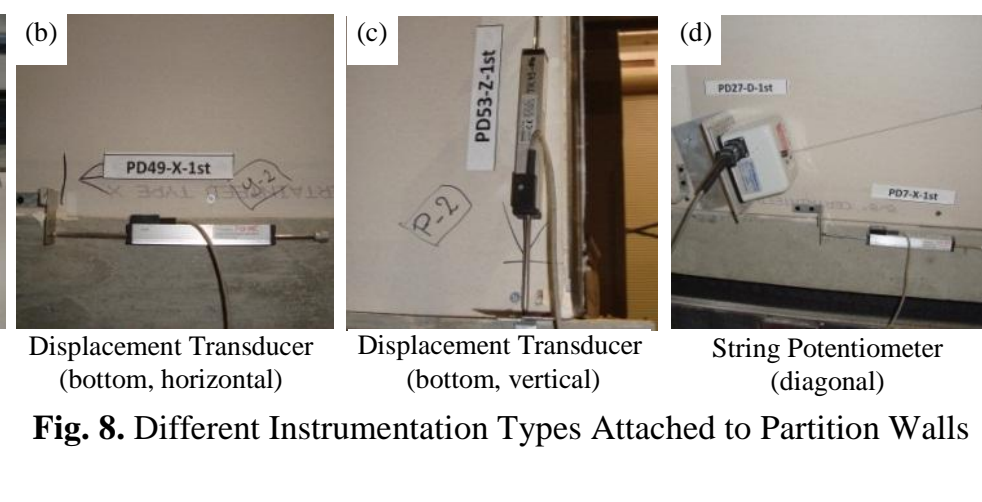

Displacement Transducer (bottom, vertical)

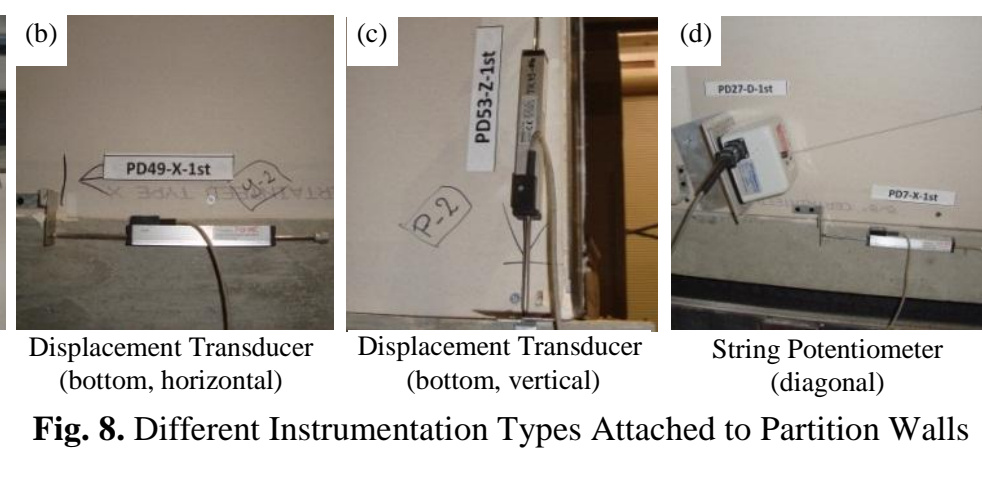

String Potentiometer (diagonal)

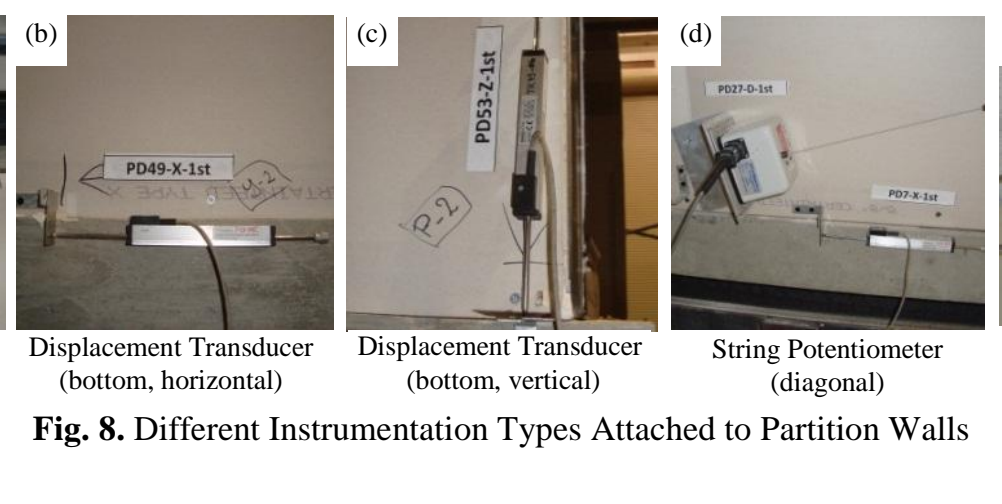

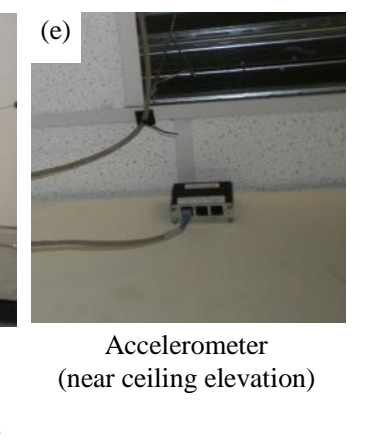

Accelerometer

(near ceiling elevation)
Fig. 8. Different Instrumentation Types Attached to Partition Walls

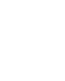

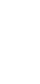

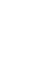
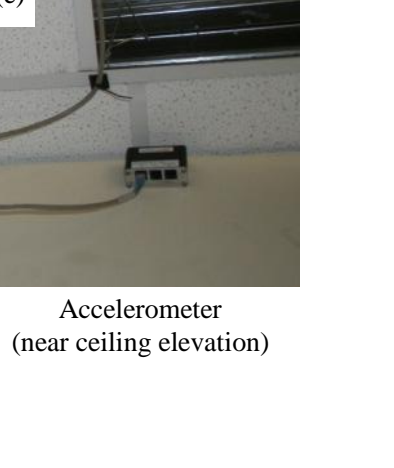

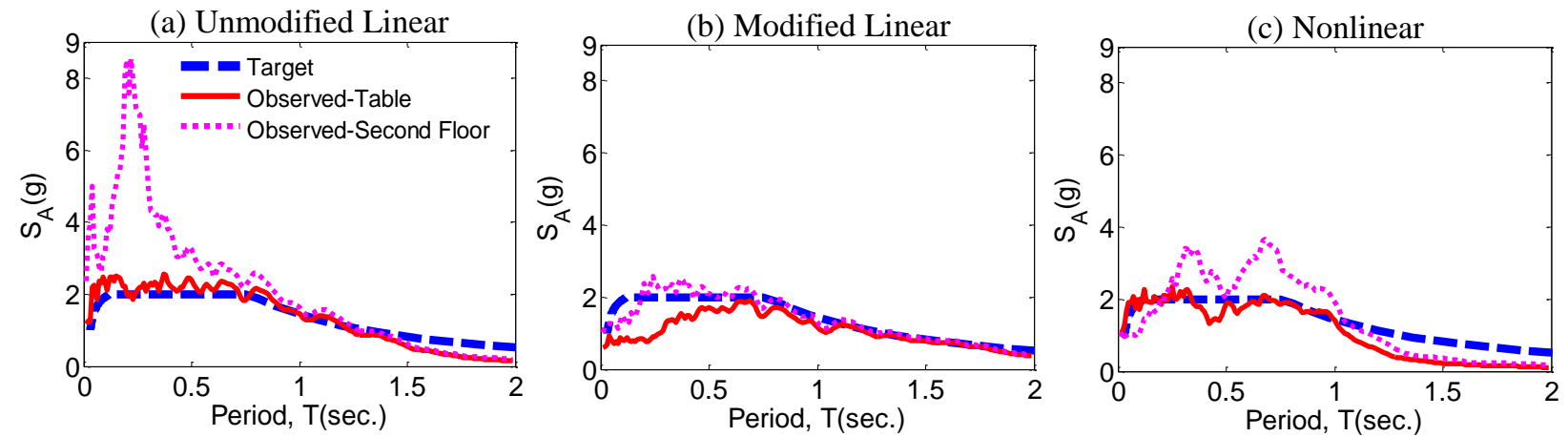

Fig. 9. Comparison between Achieved and Target 50\% IM Spectrum [Source: Soroushian et al., 2014b] 

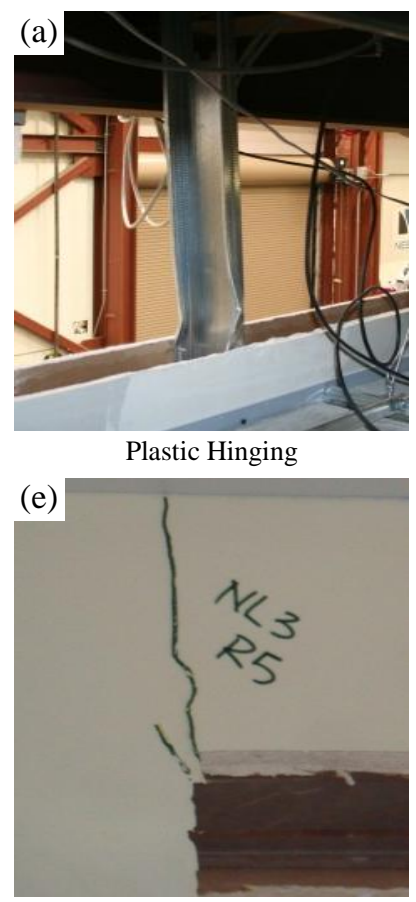

Crack at Door Corner

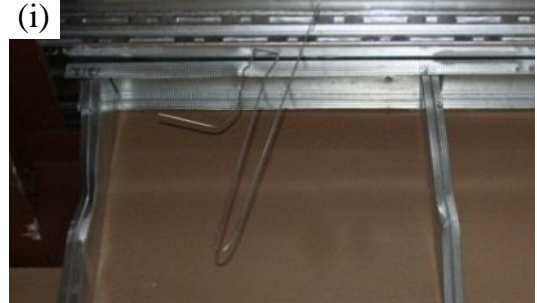

Plastic Hinging Field Studs

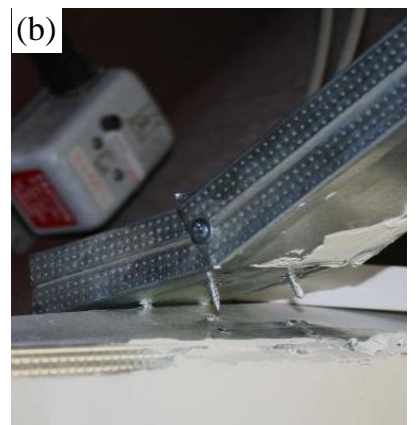

Diagonal Brace Failure

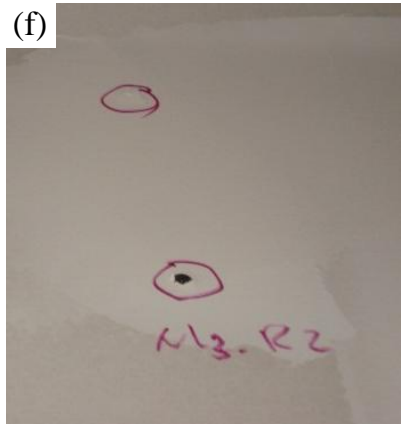

Field Screw Pop Out

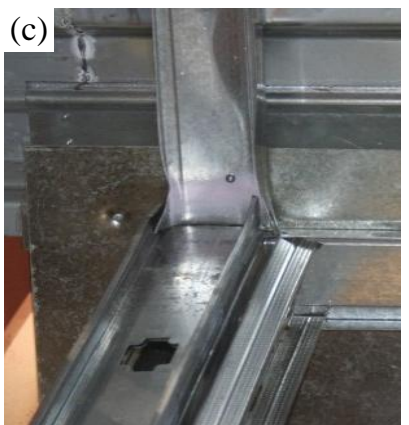

Top Track Damage

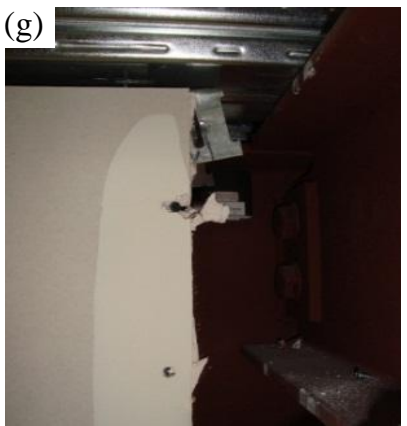

Boundary Screw Pullout

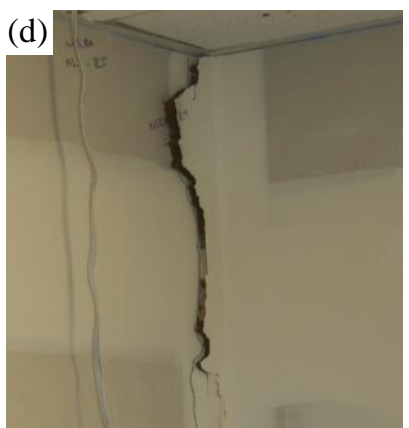

Tape Damage

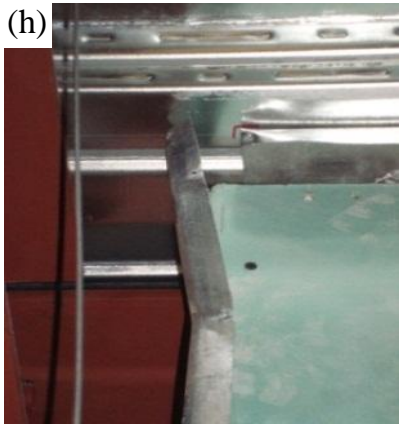

Boundary Stud Deformation

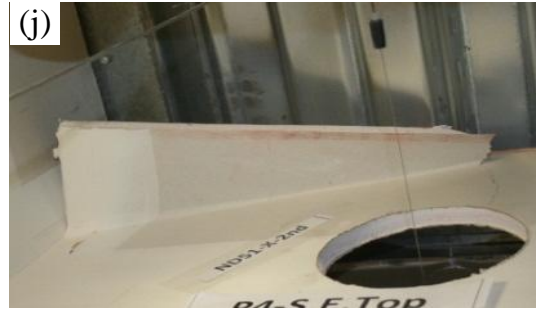

Crushing of Gypsum Board Corner

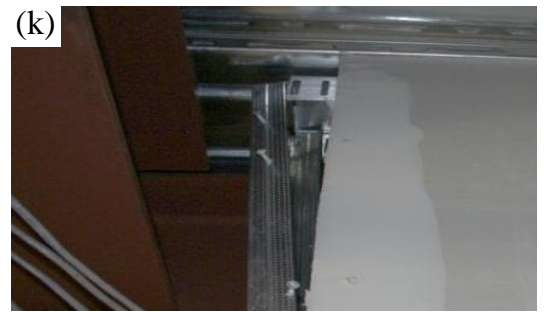

Boundary Stud Pullout

Fig. 10. Examples of Observed Damage in Partition Walls 

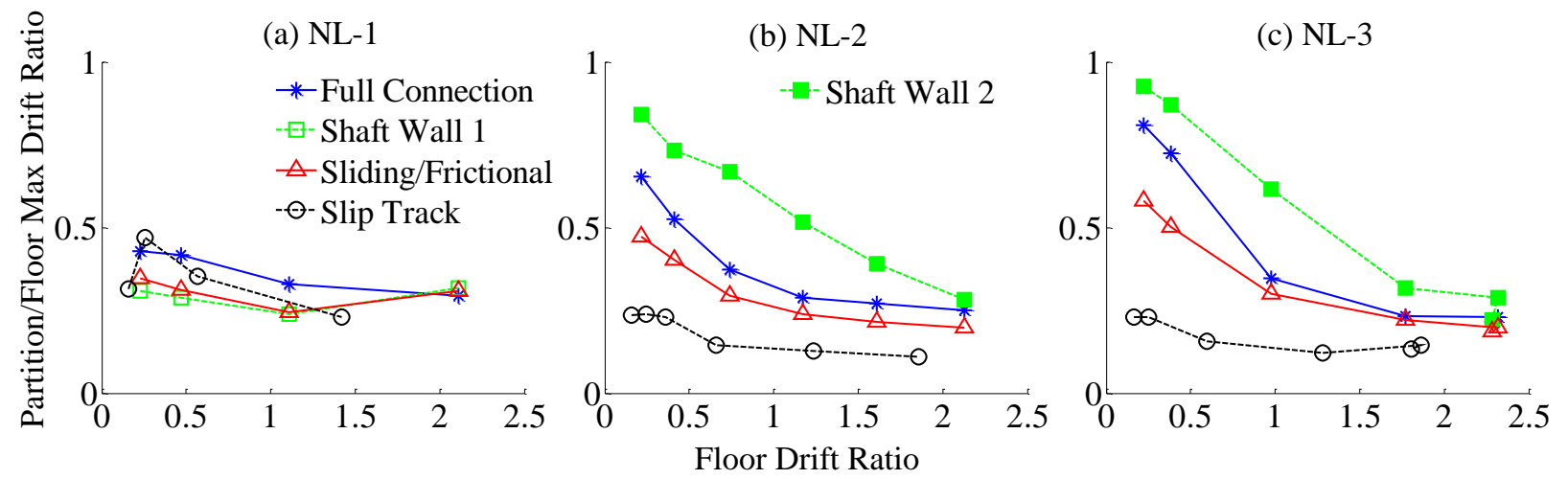

Fig. 11. Performance of Top Connections: (a) NL-1, (b) NL-2, and (c) NL-3 
(a) DS1

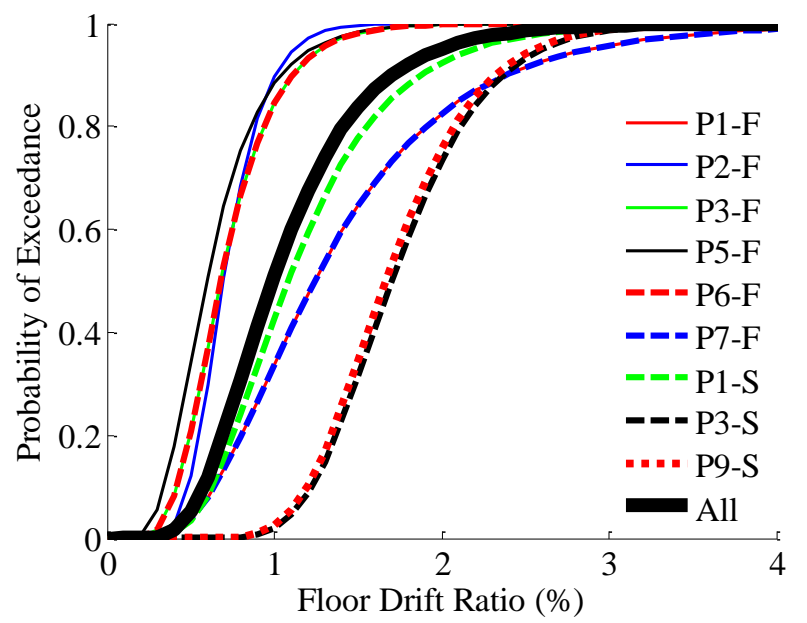

(c) DS3

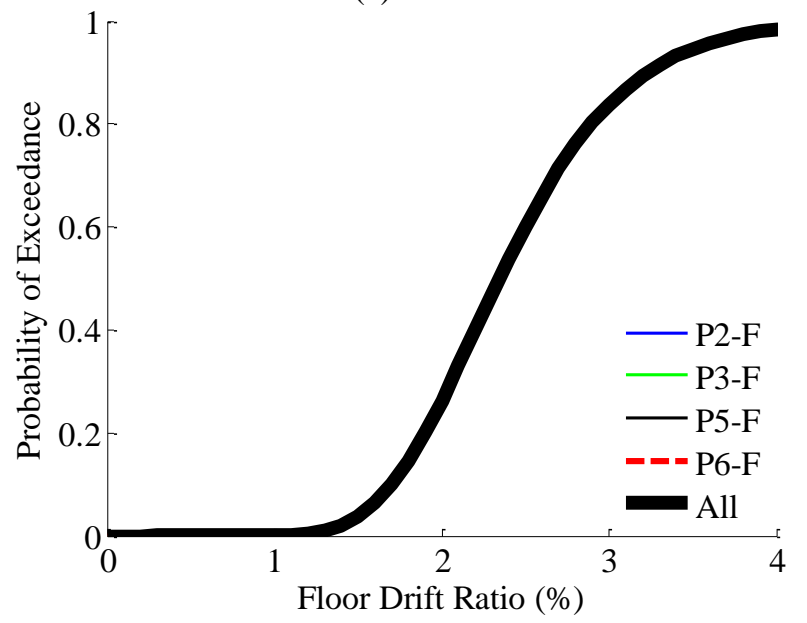

(b) DS2

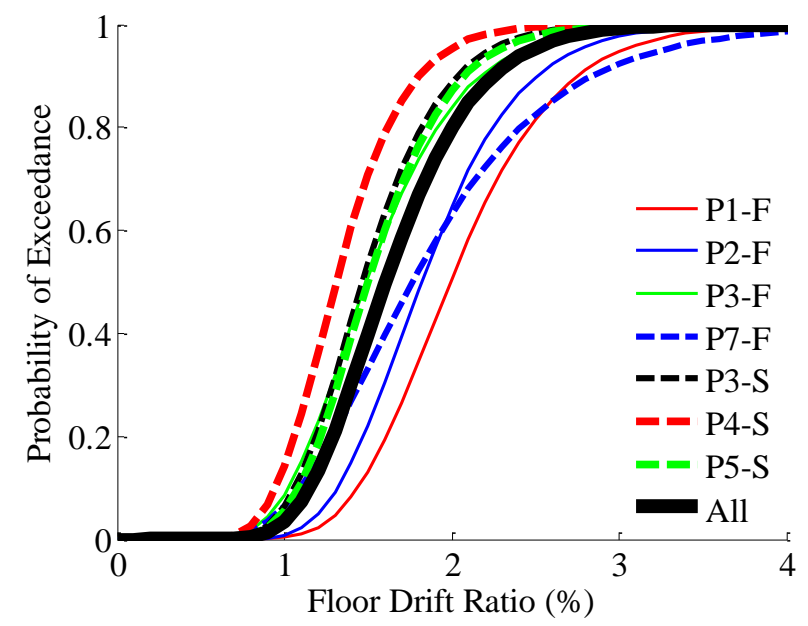

(d) Summary of Damage States

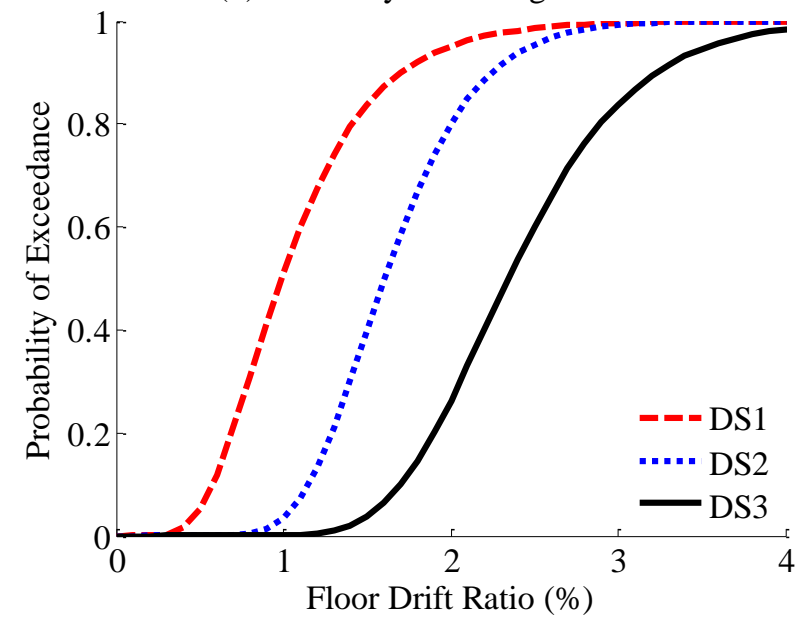

Fig. 12. Experimental Fragility Functions 
Table 1. Partition Wall Configurations

\begin{tabular}{|c|c|c|c|c|c|c|}
\hline $\begin{array}{c}\text { Partition } \\
\text { Label }\end{array}$ & $\begin{array}{c}\text { Commercial/ } \\
\text { Institutional Detail }\end{array}$ & $\begin{array}{c}\text { Wall Height/Stud } \\
\text { Height }\end{array}$ & Return Wall & $\begin{array}{c}\text { Wall Shape } \\
\text { Config. }\end{array}$ & Opening & Top Connection \\
\hline P1-F & - & Full/Full & No & $\mathrm{C}$ & - & $\begin{array}{c}\text { Shaft Wall1/Shaft } \\
\text { Wall2 }\end{array}$ \\
\hline P2-F & Commercial & Full/Full & No & S & $\begin{array}{l}\text { Door and } \\
\text { Window }\end{array}$ & Full \\
\hline P3-F & Institutional & Full/Full & No & $\mathrm{C}$ & Door & Sliding/Frictional \\
\hline P4-F & Institutional & Full/Full & Yes & $\mathrm{C}$ & Window & Sliding/Frictional \\
\hline P5-F & Institutional & Full/Full & No & $\mathrm{C}$ & - & Sliding/Frictional \\
\hline P6-F & Institutional & Full/Full & No & S & - & Sliding/Frictional \\
\hline P7-F & - & Full/Full & No & $\mathrm{C}$ & - & $\begin{array}{c}\text { Shaft Wall1/Shaft } \\
\text { Wall2 }\end{array}$ \\
\hline P8-F & - & Full/Full & Yes & $\mathrm{C}$ & - & $\begin{array}{c}\text { Shaft Wall1/Shaft } \\
\text { Wall2 }\end{array}$ \\
\hline P10-F & Commercial & Partial/Partial Braced & No & - & - & - \\
\hline P11-F & Commercial & Partial/Partial Braced & No & - & Door & - \\
\hline P1-S & Institutional & Partial/Full & No & $\mathrm{L}$ & - & Full \\
\hline P2-S & Institutional & Full/Full & No & S & $\begin{array}{l}\text { Door and } \\
\text { Window }\end{array}$ & Slip Track \\
\hline P3-S & Commercial & Full/Full & No & $\mathrm{C}$ & Door & Slip Track \\
\hline P4-S & Institutional & Full/Full & Yes & $\mathrm{C}$ & Window & Slip Track \\
\hline P5-S & Institutional & Full/Full & No & $\mathrm{C}$ & Door & Slip Track \\
\hline P6-S & Institutional & Full/Full & No & $S$ & - & Slip Track \\
\hline P7-S & Institutional & Partial/Full & No & $\mathrm{L}$ & - & Slip Track \\
\hline P8-S & Institutional & Partial/Full & Yes & $\mathrm{L}$ & - & Slip Track \\
\hline P9-S & Institutional & Partial/Full & Yes & $\mathrm{L}$ & - & Full \\
\hline P10-S & Institutional & Partial/Partial Braced & No & - & - & - \\
\hline P11-S & Institutional & Partial/Partial Braced & No & - & Door & - \\
\hline P12-S & Commercial & Partial/Partial Braced & No & - & - & - \\
\hline P13-S & Commercial & Partial/Partial Braced & No & - & Door & - \\
\hline P14-S & Commercial & Partial/Partial Braced & No & - & - & - \\
\hline P15-S & Commercial & Partial/Partial Free & No & - & - & - \\
\hline P16-S & Commercial & Partial/Partial Free & No & - & Door & - \\
\hline P17-S & Commercial & Partial/Partial Free & No & - & - & - \\
\hline
\end{tabular}


Table 2. Test-bed Responses during Linear and Nonlinear Configurations

\begin{tabular}{ccccccc}
\hline \multirow{2}{*}{ Floor } & \multicolumn{2}{c}{ Maximum Peak Floor Acceleration (g) } & \multicolumn{3}{c}{ Maximum Story Drift Ratio (\%) } \\
& Unmodified Linear & Modified Linear & Nonlinear & Unmodified Linear & Modified Linear & Nonlinear \\
\hline First & 1.59 & 1.16 & 1.22 & 0.75 & 0.66 & 2.79 \\
Second & 2.47 & 1.65 & 1.41 & 0.27 & 0.18 & 2.09 \\
\hline
\end{tabular}


Table 3. Partition Wall Test Matrix

\begin{tabular}{|c|c|c|c|c|c|c|c|c|c|c|}
\hline \multicolumn{11}{|c|}{ Linear Test } \\
\hline Test & Floor & $\begin{array}{l}\text { No. of Slip } \\
\text { Track Walls }\end{array}$ & $\begin{array}{l}\text { No. of Full } \\
\text { Conn. Walls }\end{array}$ & $\begin{array}{l}\text { No. of } \\
\text { Shaft } \\
\text { Walls } \\
\text { (Type 1) }\end{array}$ & $\begin{array}{l}\text { No. of } \\
\text { Shaft } \\
\text { Walls } \\
\text { (Type 2) }\end{array}$ & $\begin{array}{c}\text { No. of } \\
\text { Sliding/Frictional } \\
\text { Conn. Walls }\end{array}$ & $\begin{array}{c}\text { No. of Self } \\
\text { Standing } \\
\text { Partial Height } \\
\text { Walls }\end{array}$ & $\begin{array}{c}\text { No. of Full } \\
\text { Height } \\
\text { Walls w/ } \\
\text { Partial } \\
\text { Height } \\
\text { Gypsum } \\
\end{array}$ & $\begin{array}{l}\text { No. of } \\
\text { Walls that } \\
\text { only } \\
\text { Extend to } \\
\text { Ceiling }\end{array}$ & $\begin{array}{c}\text { No. of } \\
\text { Braced } \\
\text { Partial } \\
\text { Height } \\
\text { Wall }\end{array}$ \\
\hline \multirow{2}{*}{ L-1 } & 1 & 0 & 1 & 3 & 0 & 4 & 2 & 0 & 0 & 0 \\
\hline & 2 & 6 & 2 & 0 & 0 & 0 & 6 & 2 & 0 & 0 \\
\hline \multirow{2}{*}{ L-2 } & 1 & 0 & 1 & 3 & 0 & 4 & 2 & 0 & 0 & 0 \\
\hline & 2 & 6 & 2 & 0 & 0 & 0 & 6 & 2 & 0 & 0 \\
\hline \multirow{2}{*}{ L-3 } & 1 & 0 & 1 & 3 & 0 & 4 & 2 & 0 & 0 & 0 \\
\hline & 2 & 6 & 2 & 0 & 0 & 0 & 6 & 2 & 0 & 0 \\
\hline \multirow{2}{*}{ L-5 } & 1 & 0 & 1 & 3 & 0 & 4 & 0 & 0 & 0 & 2 \\
\hline & 2 & 6 & 2 & 0 & 0 & 0 & 4 & 2 & 4 & 2 \\
\hline \multirow{2}{*}{ L-6 } & 1 & 0 & 1 & 3 & 0 & 4 & 0 & 0 & 0 & 2 \\
\hline & 2 & 6 & 2 & 0 & 0 & 0 & 4 & 2 & 4 & 2 \\
\hline \multicolumn{11}{|c|}{ Nonlinear Test } \\
\hline Test & Floor & $\begin{array}{c}\text { No. of } \\
\text { Commercial } \\
\text { Slip Track } \\
\text { Walls }\end{array}$ & $\begin{array}{l}\text { No. of } \\
\text { Commercial } \\
\text { Full Conn. } \\
\text { Walls }\end{array}$ & $\begin{array}{l}\text { No. of } \\
\text { Shaft } \\
\text { Walls } \\
\text { (Type 1) }\end{array}$ & $\begin{array}{l}\text { No. of } \\
\text { Shaft } \\
\text { Walls } \\
\text { (Type 2) }\end{array}$ & $\begin{array}{c}\text { No. of } \\
\text { Sliding/Frictional } \\
\text { Conn. Walls }\end{array}$ & $\begin{array}{c}\text { No. of Self } \\
\text { Standing } \\
\text { Partial Height } \\
\text { Walls }\end{array}$ & $\begin{array}{c}\text { No. of Full } \\
\text { Height } \\
\text { Walls w/ } \\
\text { Partial } \\
\text { Height } \\
\text { Gypsum } \\
\end{array}$ & $\begin{array}{l}\text { No. of } \\
\text { Walls that } \\
\text { only } \\
\text { Extend to } \\
\text { Ceiling }\end{array}$ & $\begin{array}{c}\text { No. of } \\
\text { Braced } \\
\text { Partial } \\
\text { Height } \\
\text { Wall }\end{array}$ \\
\hline \multirow{2}{*}{ NL-1 } & 1 & $\overline{0}$ & 1 & 3 & 0 & 4 & $\overline{0}$ & $\overline{0}$ & $\overline{0}$ & 2 \\
\hline & 2 & 6 & 2 & 0 & 0 & 0 & 4 & 2 & 4 & 2 \\
\hline \multirow{2}{*}{ NL-2 } & 1 & 0 & 1 & 0 & 3 & 4 & 2 & 0 & 0 & 0 \\
\hline & 2 & 6 & 2 & 0 & 0 & 0 & 6 & 2 & 0 & 0 \\
\hline \multirow{2}{*}{ NL-3 } & 1 & 0 & 1 & 0 & 3 & 4 & 2 & 0 & 0 & 0 \\
\hline & 2 & 6 & 2 & 0 & 0 & 0 & 6 & 2 & 0 & 0 \\
\hline
\end{tabular}


Table 4. Partition Wall Damage Observed

\begin{tabular}{|c|c|c|c|}
\hline D1 & \multicolumn{3}{|c|}{ Boundary stud damage (pulled out from gypsum board, pulled out from top track, rotation, buckle). } \\
\hline D2 & \multicolumn{3}{|c|}{ Boundary stud screws pulled from gypsum board. } \\
\hline D3 & \multicolumn{3}{|c|}{ Studs sliding in top track. } \\
\hline D4 & \multicolumn{3}{|c|}{ Plastic hinging forming in studs. } \\
\hline D5 & \multicolumn{3}{|c|}{ Stud sliding or being pulled out from top track at corner connections. } \\
\hline D6 & \multicolumn{3}{|c|}{ Tape damage and cracks in wall corners. } \\
\hline D7 & \multicolumn{3}{|c|}{ Separation from transverse and longitudinal wall in top corner. } \\
\hline D8 & \multicolumn{3}{|c|}{ Crushing of gypsum wall boards (corner, due to bracing system). } \\
\hline D9 & \multicolumn{3}{|c|}{ Cracks at corners of openings. } \\
\hline D10 & \multicolumn{3}{|c|}{ Field screw pop out of gypsum board screws. } \\
\hline D11 & \multicolumn{3}{|c|}{ Popping out or damage of track screws. } \\
\hline D12 & \multicolumn{3}{|c|}{ Shot pin damage. } \\
\hline D13 & \multicolumn{3}{|c|}{ Partial height brace connection failure. } \\
\hline Partition & Test NL-1 & Test NL-2 & Test NL-3 \\
\hline P1-F & D1, D6, D7 (corner of P1-F, P8F), D8 & D1, D6, D7 (corner of P1-F, P8-F), D10 & D1, D6, D10 \\
\hline P2-F & D2, D4, D8, D10 & D1, D2, D4, D10 & D1, D2, D4, D10 \\
\hline P3-F & D1, D4, D8, D9, D10 & D1, D4, D10 & D1, D4, D9, D10 \\
\hline P4-F & D6, D9 & - & - \\
\hline P5-F & D4, D10, D11 & D1, D4, D10 & - \\
\hline P6-F & D1, D2, D4, D10 & D1, D2, D4, D10 & D1, D2, D4, D10 \\
\hline P7-F & D1, D7 (corner of P7-F, P8-F). & D1, D10 & $\begin{array}{c}\text { D1, D5 (corner of P7-F, P8-F), D6, } \\
\text { D10 }\end{array}$ \\
\hline P8-F & $\begin{array}{l}\text { D7 (corner of P1-F, P8F and P7-F, P8- } \\
\text { F) }\end{array}$ & D7 (corner of P1-F, P8-F), D11 & D5 (corner of P7-F, P8-F) \\
\hline P1-S & $\begin{array}{c}\text { D1, D4, D7 (corner of P1-S, P9-S), } \\
\text { D11 }\end{array}$ & D1, D4, D6 & D5 (corner of P1-S, P9-S), D6 \\
\hline P2-S & D1, D2, D3, D9, D10 & D1, D4 & - \\
\hline P3-S & $\begin{array}{l}\text { D3, D5 (corner of P3-S, P4-S), D8 } \\
\text { (corner of P3-S, P4-S), D9 }\end{array}$ & $\begin{array}{c}\text { D1, D2, D8 (corner of P3-S, P4-S) D10, } \\
\text { D12 }\end{array}$ & D6, D8 (corner of P3-S, P4-S) \\
\hline P4-S & $\begin{array}{c}\text { D5 (corner of P3-S, P4-S and P4-S, } \\
\text { P5-S), D7 (corner of P4-S, P5-S), D8 } \\
\text { (corner of P4-S, P3-S and P4-S, P5-S), } \\
\text { D9 }\end{array}$ & D8 (corner of P3-S, P4-S and P4-S, P5-S) & $\begin{array}{c}\text { D6, D8 (corner of P3-S, P4-S and P4- } \\
\text { S, P5-S) }\end{array}$ \\
\hline P5-S & $\begin{array}{c}\text { D3, D5 (corner of P4-S, P5-S), D7 } \\
\text { (corner of P4-S, P5-S), D8 (corner of } \\
\text { P4-S, P5-S) }\end{array}$ & D8 (corner of P4-S, P5-S) & D8 (corner of P4-S, P5-S) \\
\hline P6-S & D1, D3, D8 & D1 & D1, D8 \\
\hline P7-S & $\begin{array}{c}\text { D1, D4, D6, D7 (corner of P7-S, P8- } \\
\text { S), D11 }\end{array}$ & D1 & D1, D5 (corner of P7-S, P8-S) \\
\hline P8-S & D6, D7 (corner of P7-S, P8-S) & - & D5 (corner of P7-S, P8-S) \\
\hline P9-S & D6, D7 (corner of P1-S, P9-S) & - & D5 (corner of P1-S, P9-S) \\
\hline P10-S & D13 & - & - \\
\hline
\end{tabular}


Table 5. Partition Acceleration Amplification Factors

\begin{tabular}{|c|c|c|c|c|c|c|c|c|c|c|c|c|c|c|c|c|c|c|c|}
\hline \multirow{2}{*}{$\begin{array}{l}\text { Partition } \\
\text { Location }\end{array}$} & \multicolumn{2}{|c|}{ P4-F } & \multicolumn{2}{|c|}{ P8-F } & \multicolumn{2}{|c|}{ P10-F } & \multicolumn{2}{|c|}{ P11-F } & \multicolumn{2}{|c|}{ P4-S } & \multicolumn{2}{|c|}{ P8-S } & \multicolumn{2}{|c|}{ P10-S } & \multicolumn{2}{|c|}{ P11-S } & \multicolumn{2}{|c|}{ P14-S } & \multirow{2}{*}{$\begin{array}{c}\text { P17-S } \\
\text { B }\end{array}$} \\
\hline & $\mathbf{T}$ & B & $\mathbf{T}$ & B & $\mathbf{T}$ & B & $\mathbf{T}$ & B & $\mathbf{T}$ & B & $\mathbf{T}$ & B & $\mathbf{T}$ & B & $\mathbf{T}$ & B & $\mathbf{T}$ & B & \\
\hline \multicolumn{20}{|c|}{ Linear } \\
\hline Max & 2.1 & 2.7 & 2.1 & 2.7 & 1.9 & 2.6 & 1.8 & 2.4 & 3.0 & 4.9 & 1.6 & 2.2 & 1.3 & 1.7 & 2.1 & 2.6 & 3.1 & 4.1 & 1.6 \\
\hline Min & 1.6 & 2.1 & 1.8 & 2.3 & 1.4 & 1.8 & 1.8 & 2.4 & 2.1 & 2.8 & 1.3 & 1.8 & 1.2 & 1.7 & 1.9 & 2.6 & 1.3 & 1.7 & 1.4 \\
\hline Median & 1.9 & 2.5 & 1.9 & 2.5 & 1.6 & 2.2 & 1.8 & 2.4 & 2.4 & 3.4 & 1.5 & 2.0 & 1.3 & 1.7 & 2.0 & 2.6 & 2.2 & 3.0 & 1.5 \\
\hline \multicolumn{20}{|c|}{ Nonlinear } \\
\hline Max & 3.0 & 2.2 & 3.2 & 2.3 & 2.0 & 1.8 & 2.3 & 2.0 & 2.6 & 3.5 & 2.4 & 3.2 & 1.8 & 2.5 & 1.6 & 2.2 & 3.6 & 4.8 & 2.2 \\
\hline Min & 2.5 & 2.1 & 2.4 & 2.0 & 2.0 & 1.8 & 2.3 & 2.0 & 2.2 & 2.7 & 1.6 & 2.1 & 1.8 & 2.5 & 1.6 & 2.2 & 3.5 & 4.3 & 1.6 \\
\hline Median & 2.7 & 2.2 & 2.7 & 2.2 & 2.0 & 1.8 & 2.3 & 2.0 & 2.4 & 3.2 & 1.9 & 2.4 & 1.8 & 2.5 & 1.6 & 2.2 & 3.6 & 4.5 & 1.8 \\
\hline \multicolumn{20}{|c|}{ Summary } \\
\hline & \multicolumn{6}{|c|}{ Linear } & \multicolumn{6}{|c|}{ Nonlinear } & \multicolumn{7}{|c|}{ All } \\
\hline Max & \multicolumn{6}{|c|}{4.9} & \multicolumn{6}{|c|}{4.8} & \multicolumn{7}{|c|}{4.9} \\
\hline Min & \multicolumn{6}{|c|}{1.2} & \multicolumn{6}{|c|}{1.6} & \multicolumn{7}{|c|}{1.2} \\
\hline Median & \multicolumn{6}{|c|}{2.1} & \multicolumn{6}{|c|}{2.3} & \multicolumn{7}{|c|}{2.2} \\
\hline \multicolumn{20}{|c|}{$\mathrm{T}=$ Top connected to adjacent floor } \\
\hline $\mathrm{B}=$ Bottor & conn & cted & adja & ent $\mathrm{fl}$ & & & & & & & & & & & & & & & \\
\hline
\end{tabular}


Table 6. Damage State Definitions

Damage State

Minor Damage: Popping out or rocking of gypsum board screws (field and boundary); Cracks forming at corners of openings; Minor gypsum cracking or crushing; Joint paper damage; Sliding of studs in top track.

$\mathbf{D S}_{2}$

Local Damage: Boundary stud deformation (bending, twisting, pulling out from top track); Crushing of gypsum boards; Damage to partial height brace connection.

$\mathrm{DS}_{3}$
Severe Damage: Plastic hinging forming in field studs; tearing in steel track through slab fasteners.
Required Repair

Tape replacement at corners; gypsum board screw replacement at pop out locations; minor repairs to cracking.

Boundary stud replacement; replacing partial sections of gypsum board; replacing partial height brace system.

Removal of full gypsum board sections and replacement of field studs; replacement of new full height gypsum wall boards; replacement of top tracks. 
Table 7. Minimum Triggering Drift Ratio (First Floor Partition Walls)

\begin{tabular}{|c|c|c|c|c|c|c|c|c|c|c|c|c|c|c|c|c|c|c|c|c|}
\hline & & & \multicolumn{3}{|c|}{ P1-F } & \multicolumn{3}{|c|}{ P2-F } & \multicolumn{3}{|c|}{ P3-F } & \multicolumn{3}{|c|}{ P5-F } & \multicolumn{3}{|c|}{ P6-F } & \multicolumn{3}{|c|}{ P7-F } \\
\hline & & & 1 & 2 & 3 & 1 & 2 & 3 & 1 & 2 & 3 & 1 & 2 & 3 & 1 & 2 & 3 & 1 & 2 & 3 \\
\hline \multirow{9}{*}{$\overline{\tilde{n}}$} & \multirow{9}{*}{ 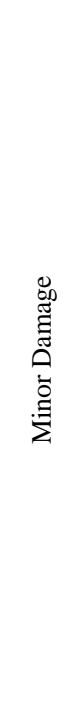 } & $\begin{array}{l}\text { Screws pulled/rocked out from gypsum board } \\
\text { (field) }\end{array}$ & - & 0.74 & 0.97 & 0.47 & 0.74 & 0.97 & 1.11 & 0.74 & 0.38 & 2.11 & 1.17 & 0.38 & 2.11 & 0.74 & 0.38 & - & 0.74 & 0.97 \\
\hline & & $\begin{array}{l}\text { Screws pulled/rocked out from gypsum board } \\
\text { (top or bottom track) }\end{array}$ & - & - & - & - & - & - & - & - & - & 0.47 & - & - & - & - & - & - & - & - \\
\hline & & $\begin{array}{l}\text { Minor stud damage (includes screw to track } \\
\text { damage) }\end{array}$ & - & 1.61 & - & - & - & - & - & - & - & - & - & - & - & - & - & - & - & - \\
\hline & & Cracks along openings (window, door) & - & - & - & - & - & - & 2.11 & & 2.32 & - & - & - & - & - & - & - & - & - \\
\hline & & $\begin{array}{l}\text { Cracks along joint paper tape, pulled tape, } \\
\text { corner beads }\end{array}$ & 2.64 & 2.13 & 0.97 & - & - & - & - & - & - & 2.64 & - & - & - & - & - & 2.64 & - & 1.77 \\
\hline & & $\begin{array}{l}\text { Screws pulled/rocked out from gypsum board } \\
\text { (Boundary Stud) }\end{array}$ & - & - & - & 2.64 & 0.74 & 0.97 & - & - & - & - & - & 0.97 & 1.11 & 1.17 & 0.97 & - & - & - \\
\hline & & $\begin{array}{l}\text { Crushing of gypsum board due to interaction } \\
\text { from the beams and partitions }\end{array}$ & - & - & - & - & - & - & 2.11 & - & - & - & - & - & - & - & - & - & - & - \\
\hline & & Sliding of stud in top track & - & - & - & - & - & - & - & - & - & - & - & - & - & - & - & - & - & - \\
\hline & & Minimum Drift Ratio Triggering DS1 & 2.64 & 0.74 & 0.97 & 0.47 & 0.74 & 0.97 & 1.11 & 0.74 & 0.38 & 0.47 & 1.17 & 0.38 & 1.11 & 0.74 & 0.38 & 2.64 & 0.74 & 0.97 \\
\hline \multirow{5}{*}{$\tilde{\tilde{\Omega}}$} & \multirow{5}{*}{ 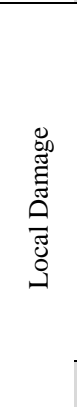 } & Crushing of gypsum board & 2.64 & - & - & 2.11 & - & - & - & - & - & - & - & - & - & - & - & - & - & - \\
\hline & & $\begin{array}{l}\text { Out-of-plane bending and cracking of gypsum } \\
\text { wallboards at wall intersections }\end{array}$ & - & - & - & - & - & - & - & - & - & - & - & - & - & - & - & - & - & - \\
\hline & & $\begin{array}{l}\text { Bending of boundary studs/detached from } \\
\text { gypsum/detached from top track }\end{array}$ & 2.11 & 1.61 & 2.32 & - & 1.61 & 1.77 & 2.11 & 1.61 & 0.97 & - & 1.61 & 0.97 & 1.11 & - & 0.97 & 2.64 & 2.13 & 0.97 \\
\hline & & $\begin{array}{l}\text { Buckling of diagonal braces (partial height } \\
\text { walls) }\end{array}$ & - & - & - & - & - & - & - & - & - & - & - & - & - & - & - & - & - & - \\
\hline & & Minimum Drift Ratio Triggering DS2 & 2.11 & 1.61 & 2.32 & 2.11 & 1.61 & 1.77 & 2.11 & 1.61 & 0.97 & - & 1.61 & 0.97 & 1.11 & - & 0.97 & 2.64 & 2.13 & 0.97 \\
\hline \multirow{3}{*}{$\tilde{\hat{n}}$} & \multirow{3}{*}{ 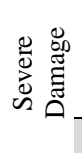 } & Tears in steel tracks through slab fasteners & - & - & - & - & - & - & - & - & - & - & - & - & - & - & - & - & - & - \\
\hline & & Plastic hinges forming in studs & - & - & - & 2.64 & 2.13 & 2.29 & 2.64 & 2.13 & 2.29 & 2.64 & 2.13 & 2.29 & 2.64 & 2.13 & 2.29 & - & - & - \\
\hline & & Minimum Drift Ratio Triggering DS3 & - & - & - & 2.64 & 2.13 & 2.29 & 2.64 & 2.13 & 2.29 & 2.64 & 2.13 & 2.29 & 2.64 & 2.13 & 2.29 & - & - & - \\
\hline
\end{tabular}


Table 7 Continued. Minimum Triggering Drift Ratio (Second Floor Partition Walls)

\begin{tabular}{|c|c|c|c|c|c|c|c|c|c|c|c|c|c|c|c|c|c|}
\hline & & & \multicolumn{3}{|c|}{ P1-S } & \multicolumn{3}{|c|}{ P3-S } & \multicolumn{3}{|c|}{ P4-S } & \multicolumn{3}{|c|}{ P5-S } & \multicolumn{3}{|c|}{ P9-S } \\
\hline & & & 1 & 2 & 3 & 1 & 2 & 3 & 1 & 2 & 3 & 1 & 2 & 3 & 1 & 2 & 3 \\
\hline \multirow{9}{*}{$\overline{\tilde{n}}$} & \multirow{9}{*}{ 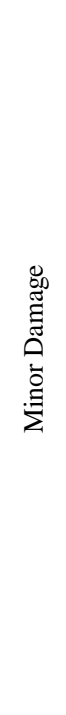 } & Screws pulled/rocked out from gypsum board (field) & - & - & - & - & - & - & - & - & - & - & - & - & - & - & - \\
\hline & & Screws pulled/rocked out from gypsum board (top and bottom track) & 0.57 & - & - & - & - & - & - & - & - & - & - & - & - & - & - \\
\hline & & Minor stud damage (includes screw to track damage) & - & 1.86 & 1.81 & - & - & - & - & - & - & - & - & - & - & - & 1.81 \\
\hline & & Cracks along openings (window, door) & - & - & - & 2.07 & - & - & 0.16 & - & - & - & - & - & - & - & - \\
\hline & & Cracks along joint paper tape, pulled tape, corner beads & 2.07 & 1.23 & 1.81 & - & - & 1.28 & - & - & 1.28 & - & - & - & 2.07 & 1.23 & 1.81 \\
\hline & & Screws pulled/rocked out from gypsum board (Boundary Stud) & - & - & - & - & 1.86 & - & - & - & - & - & - & - & - & - & - \\
\hline & & $\begin{array}{c}\text { Crushing of gypsum board due to interaction from the beams and } \\
\text { partitions }\end{array}$ & - & - & - & - & 1.86 & - & - & - & - & 2.07 & - & - & - & - & - \\
\hline & & Sliding of stud in top track & - & - & - & 2.07 & - & - & - & - & - & 2.07 & - & - & - & - & - \\
\hline & & Minimum Drift Ratio Triggering DS1 & 0.57 & 1.23 & 1.81 & 2.07 & 1.86 & 1.28 & 0.16 & - & 1.28 & 2.07 & - & - & 2.07 & 1.23 & 1.81 \\
\hline \multirow{5}{*}{$\tilde{\tilde{\Lambda}}$} & \multirow{5}{*}{ 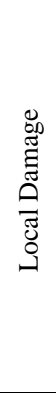 } & Crushing of gypsum board & - & - & - & 1.42 & - & - & 1.42 & - & - & 2.07 & - & - & - & - & - \\
\hline & & $\begin{array}{l}\text { Out-of-plane bending and cracking of gypsum wallboards at wall } \\
\text { intersections }\end{array}$ & - & - & - & - & 1.23 & 1.81 & 1.42 & 1.23 & 1.28 & 1.42 & 1.9 & 1.28 & - & - & - \\
\hline & & $\begin{array}{l}\text { Bending of boundary studs/detached from gypsum/detached from top } \\
\text { track }\end{array}$ & 2.07 & 1.23 & - & 2.07 & - & - & 2.07 & - & - & - & - & - & - & - & - \\
\hline & & Buckling of diagonal braces (partial height walls) & - & - & - & - & - & - & - & - & - & - & - & - & - & - & - \\
\hline & & Minimum Drift Ratio Triggering DS2 & 2.07 & 1.23 & - & 1.42 & 1.23 & 1.81 & 1.42 & 1.23 & 1.28 & 1.42 & 1.86 & 1.28 & - & - & - \\
\hline \multirow{3}{*}{$\hat{\tilde{A}}$} & \multirow{3}{*}{ 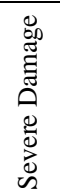 } & Tears in steel tracks through slab fasteners & - & - & - & - & 1.86 & - & - & - & - & - & - & - & - & - & - \\
\hline & & Plastic hinges forming in studs & 2.07 & 1.86 & - & - & - & - & - & - & - & - & - & - & - & - & - \\
\hline & & Minimum Drift Ratio Triggering DS3 & 2.07 & 1.86 & - & - & 1.86 & & - & - & - & - & - & - & - & - & - \\
\hline
\end{tabular}


Table 8. Summary of Fragility Parameters

\begin{tabular}{|c|c|c|c|c|c|c|c|c|c|c|c|}
\hline \multicolumn{4}{|c|}{ DS1 } & \multicolumn{4}{|c|}{ DS2 } & \multicolumn{4}{|c|}{ DS3 } \\
\hline Partition & $\mathbf{x}_{\mathbf{m}}$ & $\boldsymbol{\beta}$ & $\begin{array}{c}\text { Goodness-of-fit } \\
\text { Test }\end{array}$ & Partition & $\mathbf{x}_{\mathbf{m}}$ & $\beta$ & $\begin{array}{c}\text { Goodness-of-fit } \\
\text { Test }\end{array}$ & Partition & $\mathbf{x}_{\mathrm{m}}$ & $\beta$ & $\begin{array}{c}\text { Goodness-of-fit } \\
\text { Test }\end{array}$ \\
\hline P1-F & 1.24 & 0.51 & Pass & P1-F & 1.99 & 0.25 & Pass & P2-F & 2.34 & 0.25 & Pass \\
\hline P2-F & 0.70 & 0.28 & Pass & P2-F & 1.82 & 0.25 & Pass & P3-F & 2.34 & 0.25 & Pass \\
\hline P3-F & 0.68 & 0.38 & Pass & P3-F & 1.49 & 0.29 & Pass & P5-F & 2.34 & 0.25 & Pass \\
\hline P5-F & 0.60 & 0.43 & Pass & P7-F & 1.76 & 0.37 & Pass & P6-F & 2.34 & 0.25 & Pass \\
\hline P6-F & 0.68 & 0.38 & Pass & P3-S & 1.47 & 0.25 & Pass & & & & \\
\hline P7-F & 1.24 & 0.51 & Pass & P4-S & 1.31 & 0.25 & Pass & & & & \\
\hline P1-S & 1.08 & 0.43 & Pass & P5-S & 1.50 & 0.25 & Pass & & & & \\
\hline P3-S & 1.70 & 0.26 & Pass & & & & & & & & \\
\hline P9-S & 1.67 & 0.26 & Pass & & & & & & & & \\
\hline All & 0.99 & 0.42 & - & All & 1.61 & 0.26 & - & All & 2.34 & 0.25 & - \\
\hline
\end{tabular}


Table 9. Comparison of Drift Ratios (Correlating to Partition Damage) Reported from Various Experimental Studies (\%)

\begin{tabular}{ccccc}
\hline Damage State & Restrepo and Bersofsky [2011] & Retamales et al. [2013] & Wang et al. [2015] & UNR [2015] \\
\hline \hline DS1 & $0.05-0.75$ & $0.1-0.56$ & N/A & $0.16-2.64$ \\
DS2 & $0.5-1.5$ & $0.4-1.84$ & $0.11-1.09$ & $0.97-2.64$ \\
DS3 & $0.5-3.0$ & $0.62-2.66$ & $1.24-2.75$ & $1.86-2.64$ \\
\hline
\end{tabular}

